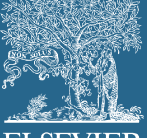

ELSEVIER

\title{
Nanocellulose as a natural source for groundbreaking applications in materials science: Today's state
}

\section{Dieter Klemm ${ }^{1} *$, Emily D. Cranston ${ }^{2}$, Dagmar Fischer ${ }^{3}$, Miguel Gama ${ }^{4}$, Stephanie A. Kedzior ${ }^{2}$, Dana Kralisch ${ }^{3,5}$, Friederike Kramer ${ }^{1}$, Tetsuo Kondo ${ }^{6}$, Tom Lindström ${ }^{7}$, Sandor Nietzsche ${ }^{8}$, Katrin Petzold-Welcke ${ }^{9}$, Falk Rauchfuß ${ }^{10}$}

\footnotetext{
${ }^{1}$ Polymet Jena Association, Wildenbruchstr. 15, 07745 Jena, Germany

${ }^{2}$ McMaster University, Department of Chemical Engineering, 1280 Main Street West, Hamilton, ON, Canada

${ }^{3}$ Department of Pharmaceutical Technology, Friedrich-Schiller-University Jena, Otto-Schott-Straße 41, 07745 Jena, Germany

${ }^{4}$ University of Minho, Center of Biological Engineering, IBB - Institute for Biotechnology and Bioengineering, Campus de Gualtar, $4710-057$ Braga, Portugal

${ }^{5}$ JeNaCell GmbH, Winzerlaer Str. 2, 07745 Jena, Germany

${ }^{6}$ Kyushu University, Graduate School of Bioresource and Bioenvironmental Sciences, Biomacromolecular Materials Lab and Biomaterial Design Lab, 6-10-1, Hakozaki, Higashi-ku, Fukuoka 812-8581, Japan

RISE Bioeconomy, Box 5604, S-114 86 Stockholm, Sweden

${ }^{8}$ University Hospital Jena, Center for Electron Microscopy, Ziegelmuehlenweg 1, 07743 Jena, Germany

9 Jenpolymer Materials UG \& Co. KG, Wildenbruchstr. 15, 07745 Jena, Germany

${ }^{10}$ Jena University Hospital, Department of General, Visceral and Vascular Surgery, Am Klinikum 1, 07747 Jena, Germany
}

Nanocelluloses are natural materials with at least one dimension in the nano-scale. They combine important cellulose properties with the features of nanomaterials and open new horizons for materials science and its applications. The field of nanocellulose materials is subdivided into three domains: biotechnologically produced bacterial nanocellulose hydrogels, mechanically delaminated cellulose nanofibers, and hydrolytically extracted cellulose nanocrystals. This review article describes today's state regarding the production, structural details, physicochemical properties, and innovative applications of these nanocelluloses. Promising technical applications including gels/foams, thickeners/stabilizers as well as reinforcing agents have been proposed and research from last five years indicates new potential for groundbreaking innovations in the areas of cosmetic products, wound dressings, drug carriers, medical implants, tissue engineering, food and composites. The current state of worldwide commercialization and the challenge of reducing nanocellulose production costs are also discussed.

\section{Introduction}

Cellulose is a fascinating biopolymer and sustainable raw material. It is one of the most important natural polymers and a key source of renewable materials on an industrial scale [1-6]. Cellulosic materials with at least one dimension in the nanometer range are referred to as nanocelluloses [7-10]. These nanocelluloses combine important cellulose properties with the features

* Corresponding author.

E-mail address: Klemm, D. (dieter.klemm@uni-jena.de). of nanomaterials. They open up groundbreaking new biomedical, environmental, and technical application areas. At the same time, nanocelluloses also represent an excellent example of the ongoing merger of biological and materials engineering.

It is convenient to subdivide nanocelluloses into three categories: bacterial nanocellulose (BNC, also known as microbial cellulose or biocellulose), cellulose nanofibrils (CNFs, also called nano/microfibrillated cellulose), and cellulose nanocrystals (CNCs, also previously referred to as nanocrystalline cellulose) as reviewed previously [10]. The production of the three types 


\author{
Nomenclature \\ ACC aqueous counter collision \\ AE-BNC aminoethyl-BNC \\ AFM atomic force microscopy \\ BNC bacterial nanocellulose \\ CBM3 carbohydrate binding module with affinity to cellulose \\ CM-BNC carboxymethyl-BNC \\ CNCs cellulose nanocrystals \\ CNFs cellulose nanofibrils \\ CP-MAS NMR cross polarization magic angle spinning nuclear \\ magnetic resonance \\ CSA Canadian Standards Association \\ DABC reactive 2,3-dialdehyde derivatives \\ DEAE-BNC diethyl aminoethyl-BNC \\ DP degree of polymerization \\ FE-SEM field-emission scanning electron microscopy \\ FTIR fourier transform infrared spectroscopy \\ $\mathrm{GAB}$ guided assembly-based biolithography \\ GE graphene \\ GRGDY glycine-arginine-glycine-aspartic acid-tyrosine \\ HoLiR Horizontal Lift Reactor
}

ISO International Organization for Standardization

MMR Tech Mobile Matrix Reservoir Technology

MWCNT multi-walled carbon nanotubes

PAA poly(acrylic acid)

PANI polyaniline

PDMS polydimethylsiloxane

PSA pressure sensitive adhesives

PVA poly(vinyl alcohol)

$\mathrm{R} \& \mathrm{D}$ research and development

RGD arginine-glycine-aspartic acid

RGDC arginine-glycine-aspartic acid-cysteine

SEM scanning electron microscopy

TAPPI Technical Association of the Pulp and Paper Industry

TC terminal complex

TEM transmission electron microscopy

TEMPO 2,2,6,6-tetramethylpiperidinyloxyl

TMAHP-BNC trimethyl ammonium betahydroxy propyl-BNC

WAXS wide-angle X-ray scattering

XG-GRGDS xyloglucan-glycine-arginine-glycine-aspartic acid-serine of nanocelluloses takes place in different ways; BNC is produced biotechnologically by bacteria, CNFs are mechanically produced by delaminating plant-based cellulose and CNCs are isolated by chemical hydrolysis or oxidation. Updating former nanocellulose data [10] a side-by-side comparison of BNC, CNF, and CNC morphology and physical properties is summarized in Table 1.

For the production and application of nanocelluloses, understanding cellulose structure is crucial. Cellulose is characterized as a high molecular weight homopolymer of $\beta$-1,4-linked anhydro-D-glucose units where every unit is corkscrewed $180^{\circ}$ with respect to its neighbours [11]. Each cellulose chain has two different end groups: one has a chemically reducing functionality (a hemiacetal unit), and the other has a pendant hydroxyl group and is the nominal nonreducing end (see Fig. 1). The number of glucose units or the degree of polymerization (DP) can be up to 20,000 , but depends on the cellulose source [11].

In plants, cellulose biosynthesis is orchestrated by specific enzymatic terminal complexes (TCs) located in the plasma membrane. The synthesis process is not fully understood, but the structure of cellulose microfibrils implies that their synthesis and assembly involve the coordination of 36 active sites [12].
TCs assemble in the Golgi apparatus where they are inactive, but move through the plasma membrane when they become activated. During cellulose synthesis, TCs move through the plasma membrane in directions that coincide with the orientation of the microtubules which have been shown to exert a direct influence on the orientation of cellulose deposition [13]. During biosynthesis, cellulose chains are aggregated in microfibrils with cross sectional dimensions ranging from 2 to $20 \mathrm{~nm}$, depending on the cellulose source [11]. The aggregation occurs via van der Waals forces and intra- and inter-molecular hydrogen bonding. If the TCs are not perturbed, they can generate a limitless supply of microfibrils with a small number of defects or amorphous domains [14].

Many studies have been performed in order to propose the nature of the supramolecular structure of cellulose including the crystal structure and dimensions, as well as defects and amorphous domains, with much debate remaining to this day [15]. In fact, even the methods to measure crystallinity are not agreed upon [16-19]. A common view is that the amorphous regions are distributed as chain dislocations on segments along the elementary fibril where the microfibrils are distorted by internal strain in the fiber and proceed to tilt and twist [20]. However,

TABLE 1

\begin{tabular}{|c|c|c|c|c|}
\hline Nanocellulose type & Length & $\begin{array}{l}\text { Cross- } \\
\text { section }\end{array}$ & $\begin{array}{l}\text { Degree of } \\
\text { polymerization }\end{array}$ & Crystallinity/crystal structure \\
\hline $\begin{array}{l}\text { Bacterial nanocellulose } \\
\text { (BNC) }\end{array}$ & Different types of nanofiber networks & $20-100 \mathrm{~nm}$ & $4000-10,000$ & $\begin{array}{l}\text { I } \alpha \text { (shell) and I } \beta \text { (core) - highest degree } \\
\text { of crystallinity }\end{array}$ \\
\hline $\begin{array}{l}\text { Cellulose nanofibrils } \\
\text { (CNF) }\end{array}$ & $0.1-2 \mu \mathrm{m}$ & $5-60 \mathrm{~nm}$ & $\geq 500$ & $\begin{array}{l}\text { Primarily I } \beta \text { - lowest degree of } \\
\text { crystallinity }\end{array}$ \\
\hline $\begin{array}{l}\text { Cellulose nanocrystals } \\
\text { (CNC) }\end{array}$ & $\begin{array}{l}100-250 \mathrm{~nm} \text { (from plant celluloses); } \\
100 \mathrm{~nm} \text { to several micrometers (from } \\
\text { celluloses of tunicates, algae, } \\
\text { bacteria) }\end{array}$ & $5-70 \mathrm{~nm}$ & $500-15,000$ & $\begin{array}{l}\text { Primarily } \mid \beta \text {, sometimes } \mid \alpha-\text { medium } \\
\text { degree of crystallinity }\end{array}$ \\
\hline
\end{tabular}




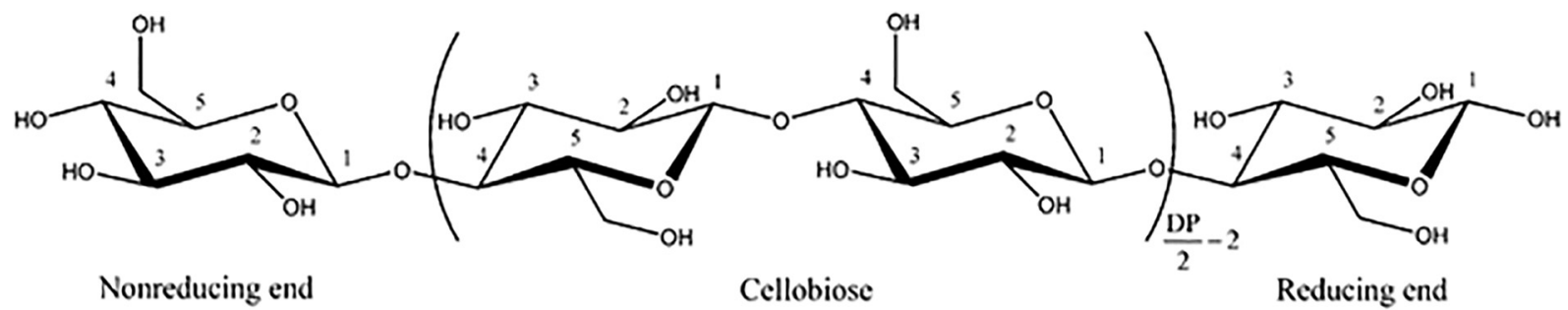

FIGURE 1

Molecular structure of cellulose.

more recent studies indicate that amorphous regions may be very small, and/or are probably more correctly only "slightly disordered" and not fully amorphous, or likely form a shell or outer core around the more crystalline regions [21,22]. It is similarly of great interest to understand the crystallinity of cellulose in nature as Agarwal et al. have now proposed that drying/processing of wood pulp is necessary to induce "measurable" crystallinity and for example, CNCs cannot be produced from never-dried wood (using the conditions tested in their work) [23]. This has important implications if processing of pulp fibers can help to improve crystallinity and therefore the yield of nanocelluloses [24,25].

Microorganisms are also able to produce nanocellulose directly [10]. The most commonly used microorganisms are acetic acid bacteria of the genus Gluconacetobacter (synonym Komagataeibacter). This bacterial nanocellulose is synthesized as a formstable water-containing nanofiber network, which is made of $1 \%$ cellulose and $99 \%$ water. The diameter of the nanofibers is between 20 and $100 \mathrm{~nm}$. In this bacterium, the enzyme cellulose synthase is present on the cytoplasmic membrane, and the cellulose product is obtained extracellularly.

The bacterium produces pure cellulose. A single cell may polymerize up to 200,000 glucose residues per second into $\beta-1,4-$ glucan chains. Assembly of the ribbon takes place in several steps. The cellulose-synthesizing sites on the cell surface are made of pores that are arranged in a linear row. Each pore covers a $10-\mathrm{nm}$ particle that consists of the cellulose-synthesizing enzymes involved in the polymerization reaction and accessory proteins possibly involved in other functions. Each 10-nm particle produces a number of glucan chains that form a 1.5-nm subelementary fibril. The sub-elementary fibrils together form the microfibril. The biosynthetic pathway for cellulose biosynthesis is very well understood in this bacterium. It involves stepwise phosphorylation of glucose and formation of UDP-glucose, which is used as a substrate by the enzyme cellulose synthase [26]. This process yields highly crystalline BNC.

In contrast, CNFs and CNCs are obtained through isolation processes from macroscale cellulosic materials as previously mentioned. The isolation of CNFs occurs via mechanical disintegration, yielding particles containing both disordered and crystalline regions. The overall goal in CNF production is to maintain the crystalline form and also to maintain the degree of polymerization as much as possible of the delaminated CNF filaments. The isolation of CNCs by acid hydrolysis (and less commonly by oxidation) selectively degrades disordered cellulose chains, resulting in highly crystalline nanoparticles. The
CSA Standard for cellulose nanomaterials defines CNFs as cellulosic objects composed of at least one primary fibril, containing crystalline and amorphous regions, with aspect ratios usually greater than 50. CNCs are defined as having high crystallinity, a high degree of short range order, and consisting of $>99 \%$ pure cellulose [27].

In the present review article, the production (including international market launch), structural details, physicochemical properties, and innovative applications of BNC, CNFs, and CNCs are described. The search for new applications for these nanocelluloses is an important driving force for research and development (R\&D) in research groups and increasingly in companies. A snapshot of "today's state" is given in the corresponding subchapters of the review.

\section{Bacterial nanocellulose}

\section{Properties and potential applications of BNC}

$\mathrm{BNC}$ is widespread in nature. It is generated wherever the fermentation of sugars and plant carbohydrates via microorganisms takes place. Its biological formation opens up the opportunity to develop biotechnological production pathways to significantly influence and control the final BNC material features. The unique properties of native BNC include, in particular, high purity (pure cellulose), a nanofiber network structure and a high water content of $99 \%$ in the form of mechanically and thermally stable hydrogel bodies. These gel bodies are generated in planar form (fleeces/pellicles) with the same dimensions as the cultivation reservoir or can be brought into a complex threedimensional shape by use of templates.

BNC hydrogels can be dried by different methods: air and press drying (both at room temperature or heating up to about $200{ }^{\circ} \mathrm{C}$ ), freeze drying as well as critical point drying. Dewatering can also be achieved by stepwise solvent exchange. The drying method has a significant effect on the resulting BNC properties. Air-drying BNC leads to a loss of the characteristic threedimensional network structure as shown by intense wrinkling as a result of strong shrinkage, superficial hornification, fiber aggregation, and reduced porosity. The same holds true for drying by pressing, but under these conditions wrinkling is avoided. Furthermore, BNC becomes brittle when dried completely. To prevent brittleness, a stepwise water reduction leads to an increased concentration of cellulose in the sample. This is of importance for applications of BNC hydrogels as medical implants [28]. Another method of brittleness prevention is the post-modification of BNC with selected additives like inorganic salts or polyalcohols which results not only in a fast reswelling 
behavior (so called shape-memory effect) after air-drying but also in more flexible storage forms [29].

Freeze drying and critical point drying are gentle procedures, which retain the original nanofiber structure. In both cases, the water is replaced by air to form aerogels. In order to critically point dry a BNC sample, a stepwise solvent exchange from water to acetone or ethanol (resulting in an organogel) is an intermediate material prepared before the alcohol is exchanged to liquid carbon dioxide. Both freeze drying and critical point drying are well suited for the preparation of BNC samples for scanning electron microscopy and other characterization. Even though these materials are dried completely they are more compliant and not brittle.

One of the first commercially available BNC products was Nata de Coco, a popular dessert in Asian countries [30-32]. More recently, in some applications BNC shows potential to outperform the currently used celluloses in the food industry as a promising novel hydrocolloid additive. It should be noted that large efforts are currently underway to enhance BNC from a food to a new generation of nature-based sophisticated materials. During the last couple of years, several young companies worldwide have started to bring such BNC-based products to the market. Examples are DePuy Synthes, USA (SYNTHECEL ${ }^{\circledR}$ Dura Repair (implant)), JeNaCell GmbH, Germany (epicite ${ }^{\text {hydro }}$ (wound dressing)), and BOWIL, Poland (Celmat (wound dressing)).

Although BNC consists of biopersistent elongated fibers with nanosized diameters, (i.e., structures that are the subject of intensive nanosafety discussions), BNC is categorized as a highly biocompatible material [9]. This has been reported for mice, rats, rabbits, and pigs without severe signs of inflammation, fibrotic capsule formation, or toxicity on the genetic and cellular level as a result of in vitro-, ex ovo-, and in vivo-investigations even in long-term applications of up to one year [33-37]. Based on this compatibility and non-toxicity, there has been a recent increase in publications focused on developing BNC medical applications spanning wound dressings to medical implants. It is worth mentioning that wound dressings made of BNC are currently on the market and even some BNC implants have made their way to multi-center clinical studies [28]. In general, BNC is one of the very few biomaterials that represents a completely novel solution to hitherto unresolved problems in regenerative medicine.

In the recent years, enormous progress in BNC cultivation techniques has been made which provides access to controlled production conditions, high-quality materials with the possibility of upscaling in a way that may broaden BNC use. However, reducing the production costs remains a crucial challenge. The key measures to reduce BNC production costs are (i) the use of alternative feedstocks especially plant wastes, (ii) novel bioreactor designs and their automation and (iii) scale-up (details in Section Up-scaled production).

In parallel, many excellent review articles [10,38-41] and books [42-45] on BNC have been published and the scientific literature continues to grow exponentially (Fig. 2). In the following subchapters, selected current and forward-looking hot topics of $\mathrm{BNC}$ research, development, and applications are discussed in more detail including production of BNC and scale-up, product design, and structural characterization. Moreover, modification of BNC for medical applications and current examples for the

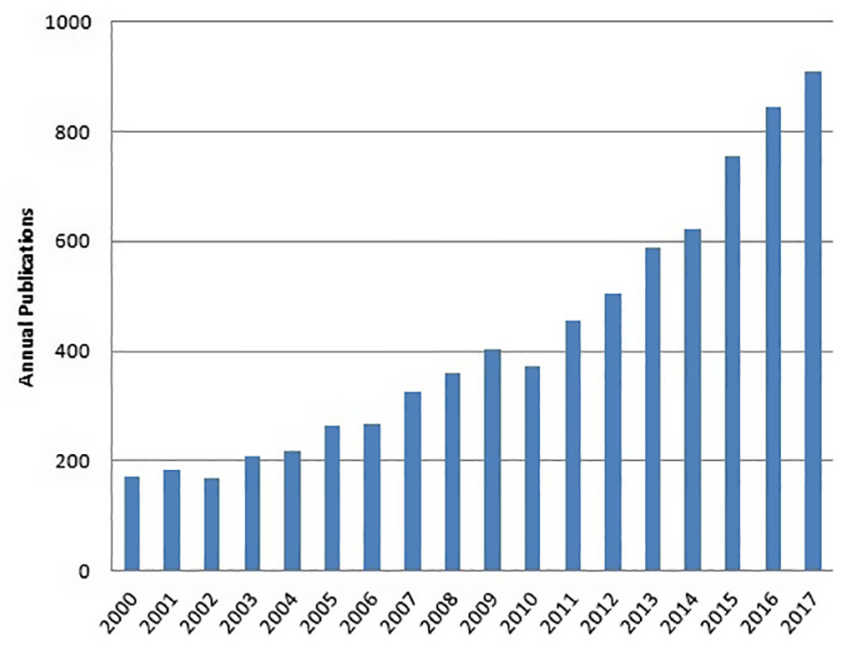

\section{FIGURE 2}

Annual publications from 2000 to 2017 (compiled Sep. 2017). Searches were done with ScienceDirect using the topics: bacterial cellulose, bacterial nanocellulose, microbial cellulose, BNC, bacterially synthesized cellulose and biocellulose.

development of medical implants based on BNC hydrogels are presented.

\section{BNC production and design}

Up-scaled production

In the past and currently, the majority of commercial products made from BNC use agriculturally produced BNC, called biocellulose. The production process is still done by hand but produces BNC in large quantities of 500-1500 tons per year per producer in the traditional fermentation industry of Nata de Coco farms, mainly situated in Asian countries such as Indonesia and the Philippines $[46,47]$. Biocellulose fleeces are typically cultivated for 7-14 days in plastic pans or jars at temperatures ranging from 23 to $32{ }^{\circ} \mathrm{C}$ depending on the surrounding environmental conditions [30]. One plastic jar containing, for example, 500-g Nata de Coco culture broth typically yields 1.5-g dry biocellulose [48]. The implementation of advances and new scientific findings in these biocellulose cultivation procedures are rather slow due to family-owned companies organized in a cottage industry style and the fact that production often occurs in rural areas with little infrastructure [47]. Nevertheless, biocellulose is well suited for, and mainly used in, the food and cosmetics industries and is traded worldwide. The utilization of this type of BNC in medical, pharmaceutical, and advanced technical applications is, however, hampered by varying culture conditions and feedstock qualities, possible impurities, and a comparatively low material stability [49].

The need for high-quality BNC has triggered R\&D of biotechnological cultivation techniques as well as the formation of several new companies worldwide. In general, methods under investigation for biotechnological BNC production range from agitated to static cultivation approaches using batch or fedbatch up to continuous cultivation methods [50]. Typical bioreactors such as aerated fermenters or bubble columns, and less conventional rotary disc reactors, have been utilized [51]. Furthermore, specific bioreactor concepts to produce tubular BNC, 
which is ideally suited as an implant material, have been designed [52,53].

The choice of cultivation technique depends on the intended application of the BNC material, since the cellulose supramolecular structure and its physical and mechanical properties are influenced by the production method. Depending on the specific bacteria strain, process parameters such as composition of the culture medium, temperature, $\mathrm{pH}$, and dissolved oxygen content determine the productivity of the bioprocess [48] and should be controlled in order to obtain reproducible material properties of the harvested BNC. Many research groups have also intensely investigated the use of plant waste materials (e.g., molasses, corn steep liquor, and rotten fruits) as carbon source and nutrients in order to reduce the production costs $[40,54]$. For some substrates such as sugar cane molasses or konjac flour, even higher yields than for sucrose and fructose or glucose were found $[55,56]$. These findings pave the way for more cost efficient BNC production. However, one has to keep in mind that these feedstocks are not suited for applications with high purity and reproducibility requirements, e.g., medical devices, implants, or drug delivery systems made of BNC.

Even under industrial, controlled conditions, planar BNC is still mostly produced by a conventional batch cultivation in pans. Alternatively, thin layer cultivation on solid phases such as agar [57], silicone rubber [58], and on different porous membranes [59] or plastic composite supports [60] have been described. On these supports, the BNC can be accumulated at the interface of the air and culture medium.

Cultivation under shaking and stirring in submerged cultures as well as several modified agitated production procedures have been thoroughly studied as well. These methods provide a fibrous or pellet-like material [61]. The yield of the BNC obtained tends to be lower than in static culture as the shear stresses promote mutation of bacteria into non-cellulose producing strains [48], but single strains with higher resistance have been already found. Stirred-tank and air-lift reactors are the most commonly used bioreactors for BNC generation under agitated cultivation conditions [62]. Successful pilot-scale production under agitated conditions was demonstrated by Song and colleagues using a 50$\mathrm{L}$ modified airlift-type bubble column bioreactor and utilizing saccharified food waste as feedstock [63].

A novel type of bioreactor called a Horizontal Lift Reactor (HoLiR) was developed by Kralisch and colleagues [64]. It combines strategies from both static and agitated cultivation and allows for a (semi-)continuous cultivation and harvesting of planar fleeces and foils of BNC. The authors published the successful transfer of the approach to pilot-scale processing in a $180 \mathrm{~L}$ HoLiR bioreactor and the combination with a continuous down-stream processing unit (see Fig. 3) [65]. The replacement of batch by (semi-)continuous processing and the scale-up resulted in a significant reduction of production costs $[11,26]$. The controlled, steady-state cultivation conditions within the HoLiR are also the reason for the reproducible generation of high-quality BNC materials characterized by a very homogeneous network and a uniform surface.

The up-scaled and automated HoLiR production process is now applied by the German company JeNaCell under rigorous quality management to produce advanced BNC-based products

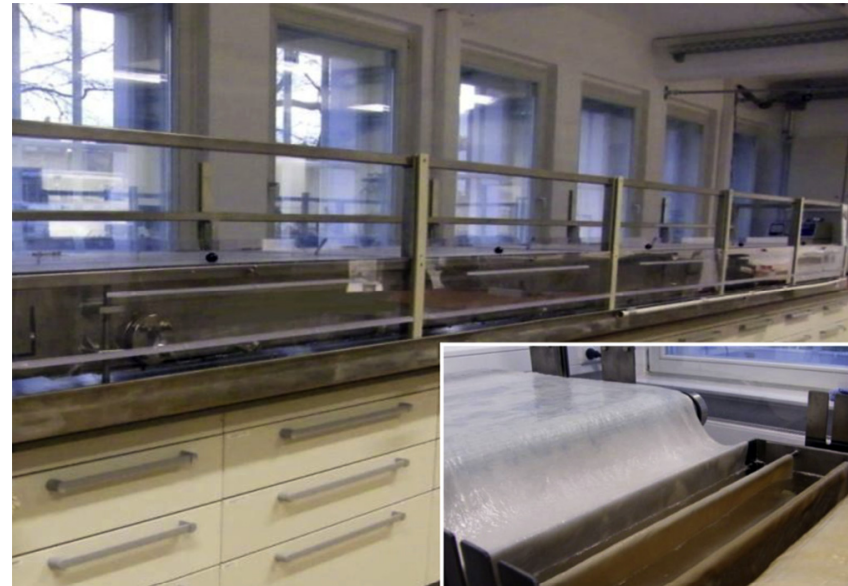

\section{FIGURE 3}

Picture of HoLiR pilot-plant and of the resulting homogenous BNC fleece [65].

for medical and dermatological applications. Other BNC producers include BOWIL Biotech in Poland, S2Medical in Sweden, fzmb in Germany, and DePuy Synthes in Pennsylvania, USA.

In summary, the up-scaling and industrialization of BNC production, urgently required to meet the large market potential of this high-performance biopolymer in many applications, has successfully begun but is still small compared to the annual production capacity of the Nata de Coco industry. In parallel to the development of new approaches using biotechnological reactors, improved process design and scale-up, fundamental studies of the biosynthesis of BNC remain crucial. A better understanding of the biosynthetic process and structural characterization of the functional cellulose synthase complexes will provide valuable insights into the bioprocess and will further increase the efficiency and controllability of the BNC production process [66].

Layer-by-layer design of planar BNC materials, coatings, and composites In most cases, BNC is produced by cultivation of acetic acid bacteria in an aqueous culture medium under static conditions, as described previously. Fig. 4a, shows how a BNC hydrogel is formed at the surface of a liquid culture medium, which is in direct contact with the air. Scale-up production techniques are described in the preceding chapter. The static process allows variation of the reservoir geometry, temperature, type of culture medium, and the bacterial strain to influence the properties and tailor the resulting BNC for a variety of applications.

In the last few years, the R\&D focus of Klemm and co-workers [67-69] has been on the creation of additional control elements for BNC production. In the resulting process, the design of not only the shape and dimension of the hydrogel bodies, but also the most important BNC properties such as structure of the surfaces and the internal nanofiber network architecture, can be reproducibly controlled via control elements of the bioreactor. In the case of the developed dynamic cultivation (see Fig. 4b), a matrix that contains the templates is moving periodically between the air space and the reservoir, which is filled with the liquid culture medium. During dipping, the template is loaded with culture medium and bacteria. After leaving the liquid, the BNC formation takes place exclusively on the template surface. 


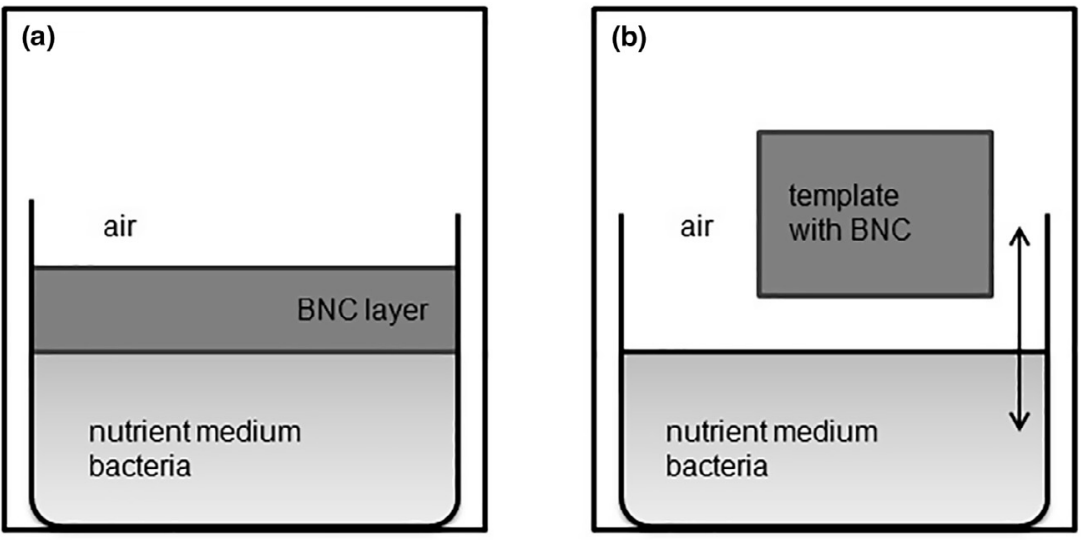

\section{FIGURE 4}

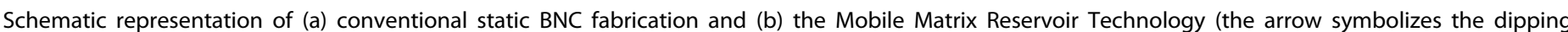
process of the template).

This dipping process causes turbulence in the culture medium, and the BNC formation at the surface area of the liquid culture cannot take place. With this Mobile Matrix Reservoir Technology (MMR Tech), it is possible to produce flat BNC hydrogels. After biosynthesis, the hydrogels have to be removed from the template, purified in boiling aqueous sodium hydroxide solution, and washed with water. The resulting material is characterized by two different surfaces - one was in contact with the air, the other one was in contact with the template.

The unique feature of this MMR Tech is the layer-by-layer BNC formation. In contrast to the usual static BNC production, with MMR Tech, self-contained layers are generated because of the air contact after each immersion step. Nevertheless, the connection between these single self-contained layers is so strong that the hydrogel assembled does not delaminate.

The MMR Tech allows for the production of completely novel types of BNC materials. Additional control elements for the design of the surface structure and the network architecture of the bulk are the material, shape, dimensions, and the surface texture of the template as well as the moving mode of the matrix. Moreover, the layer-by-layer formation is also useful for coating different materials with BNC layers, using the material in question as the template. The strength of the substrate-layer interaction depends mainly on the hydrophilicity and the porosity of the template material. Partial or complete drying - in air or by heating - causes the coated layers to shrink offering even stronger attachment.

The layer-by-layer formation also allows for the important possibility of incorporating different types of dissolved as well as dispersed additives into the BNC nanofiber architecture. In the usual static method, solid additives can only be inserted into the lowest layer of the resulting BNC hydrogel facing the liquid culture medium. In one exciting example, the MMR Tech enabled the development of BNC-CNF hybrids, where the nonmoldable CNF material was incorporated into the molded BNC body. The culture medium contained dispersed CNF, which were attached to the template surface as the template leaves the culture medium. When CNFs labeled with red dye was used, the cross section of the resulting hydrogel was homogeneously stained, showing the incorporation of CNFs throughout the entire hydrogel cross-section.
By using MMR Tech, molded BNC hydrogels, such as pouches and polymer-reinforced composites can be produced. For composite assembly, the water contained in the shaped BNC hydrogel is exchanged to a mixture of monomers and crosslinkers, e.g., precursors for epoxy resins as well as thermally or photochemically polymerizable acrylate and methacrylate systems. During crosslinking polymerization, the original shape of the BNC material remains unchanged. In this way, it is possible to produce fiber-reinforced polymer composites in terms of polymerenhanced shaped BNC fiber structures.

\section{BNC-relevant electron microscopy procedure}

Since single fibers of BNC have a thickness in the range of tens of nanometers, electron microscopy is well suited to study their morphological properties. In order to investigate whole pieces of actual BNC components or products, scanning electron microscopy (SEM) can be used as it does not require the preparation of ultrathin sections as required for transmission electron microscopy (TEM). The notably large depth of field of SEM is very helpful to image three-dimensional BNC objects. Nevertheless, a field-emission SEM should be used to provide magnifications up to $100,000 \times$.

Fresh BNC samples contain a high amount of water - the embedded water has a substantial contribution to the shape of the object. This water has to be removed during sample preparation for SEM to be vacuum stable as well as to reveal the cellulose fibers. Simple air-drying leads to a collapsed and altered structure due to the surface and interfacial tension of the evaporating water, respectively. This is well known from the treatment of other biological samples like cells or tissue [70] and must be avoided to obtain meaningful micrographs. Two alternative ways of drying that are well established in SEM sample preparation are: freeze drying and critical-point drying (see Fig. 5). Both techniques avoid the liquid-gas phase transition by either staying in the solid phase followed by sublimation or the critical state where a liquid and its vapor can coexist. While critical-point drying is usually used for cells and tissues, freeze drying is also useful for BNC samples since they are not sensitive to freezing damage. In our experience, no differences were observed between freeze drying and critical-point drying techniques. 
(a)

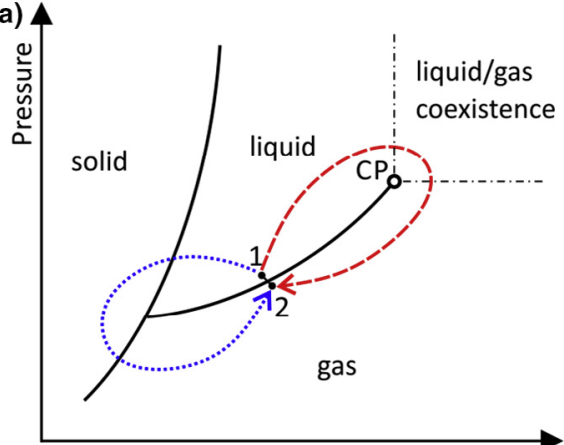

Temperature
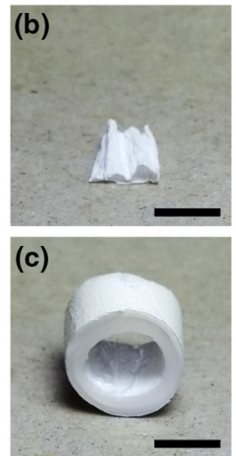

\section{FIGURE 5}

(a) Schematic phase diagram showing the drying process (1 to 2 ). To avoid the liquid-gas phase transition either freeze-drying (dotted) or critical-point (CP) drying (dashed) is possible. An air-dried BNC sample (b) is clearly collapsed and shrunk in comparison to a freeze-dried one (c) of the same batch. Scale bars are $2 \mathrm{~mm}$.

Dry BNC samples are very sensitive to touch even if probed very gently with fine tweezers. Areas of interest for imaging should never be touched with handling tools or by the wall of the container. The same problem arises if inner parts are to be explored, e.g., by cross sectioning. The only way to show untouched areas is to prepare a guiding cut and further tear the region of interest apart (see Fig. 6).

Finally, the dry BNC samples must be glued onto SEM sample holders and their surface must be coated to be electrically conductive. The glue should have a higher viscosity and a low amount of solvent in order to avoid infiltrating the sample more than necessary. Good results can be obtained using conducting carbon cement (Leit-C) and allowing it to briefly pre-dry. The surface can be treated by sputter coating with gold or platinum. Because of the porosity of the sample material, the real surface area is notably larger than the surface seen by microscopy. Therefore the specified layer thickness at the sputter device has to be set much higher than the thickness actually applied to the individual BNC fibers since the target thickness always refers to a perfectly flat surface. A nominal value of approximately $20 \mathrm{~nm}$

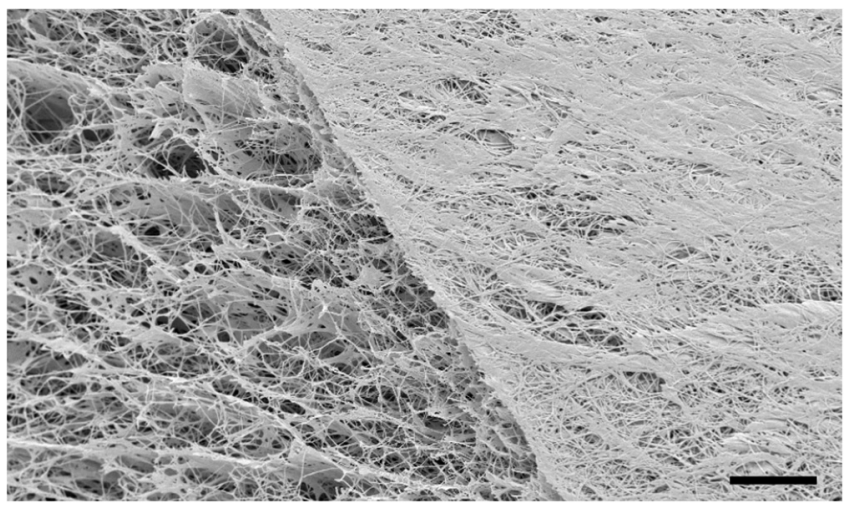

\section{FIGURE 6}

SEM image of a cross section of a BNC piece showing artifacts introduced by touching. The sample was cut by a razorblade from the right hand side halfway leaving a crushed surface, the rest was torn apart. Original magnification $1000 \times$, scale bar is $10 \mu \mathrm{m}$.

effectively prevents surface charging and does not visibly load the BNC fibers with metal.

\section{Preparation of single BNC fibers}

Recently, a novel method to pulverize hierarchically organized bio-based materials into nano-objects using only the collision energy of dual water jets was invented by Kondo et al. [71-79]. This technique termed "aqueous counter collision" (ACC) successfully dissociates the weaker intermolecular interactions such as van der Waals forces in bio-based materials without any chemical modification. In the ACC system, an aqueous suspension containing micron-sized material is pre-divided between two facing nozzles as shown in Fig. 7. Water jets from each nozzle then rapidly impinge on each other, resulting in the nanopulverization of the dispersed sample. In the collision of dual water jets in the ACC treatment, ejecting water molecules are assumed to transfer the kinetic energy toward the sample in order to hierarchically overcome the van der Waals forces [72].

ACC can be used to produce CNFs, in the case of wood pulp cellulose samples, the width of the nanofibrils is reduced to 10-15 nm [72]. When the ACC treatment is applied to a BNC pellicle, the BNC network that is held together by a combination of hydrogen bonds and van der Waals forces is easily and rapidly liberated into single cellulose nanofibers (single is equivalent to "individual") [73]. The characterization of the BNC fibers is described in the following section [73].

Morphological aspects of a single BNC [3] - Before ACC, the network structure of fibers in the pellicle is visible by polarized optical microscopy. After a few collisions (=a Pass) of the ACC treatment, nothing is observed using a polarized optical microscope, but a BNC fiber with a nano-sized width can be observed by TEM. The sizes of BNC depending on Pass number are listed in Table 2. Width of the BNC fiber decreases with increasing Pass number in ACC treatment.

The nano-pulverization by ACC exposes internal faces in native $\mathrm{BNC}$ to the surface which increases the surface area of the new BNC, as shown by TEM [73] (specific aspect area $/ \mathrm{m}^{2} \times \mathrm{g}^{-1}$ $=43.0$ (0 Pass), 54.5 (30 Pass), and 55.9 (60 Pass)). Width and length of BNC fibers is difficult to measure because of the selfaggregation on the TEM grid during sample preparation. Aggregation-free BNC on the grid is, therefore, selectively employed for the measurements of width and length, respectively.

(i) Transmission electron microscopy - Observation by TEM is employed for measurements of both width and length of a single BNC fiber using acquired digitized images. The essential procedure is presented in detail:

- To avoid self-aggregation of the nanofibers, $10 \mathrm{~mL}$ of ca. $0.04 \%(\mathrm{w} / \mathrm{v})$ aqueous suspension of BNC is mixed with $10 \mathrm{~mL}$ of $0.4 \%(\mathrm{w} / \mathrm{w})$ of poly(vinyl alcohol) (PVA) aqueous solution. The mixture is stirred at $50{ }^{\circ} \mathrm{C}$ for 3 days before it is diluted to $1 / 10$ concentration using deionized water.

- A mixture of $1 \mathrm{~mL}$ of this suspension is added to $9 \mathrm{~mL}$ of $0.2 \%$ uranium acetate aqueous solution is sonicated for $10 \mathrm{~s}$, mounted on copper grids and finally air-dried.

- The BNC on the grid is observed using TEM at $80 \mathrm{kV}$ of the accelerating voltage. 


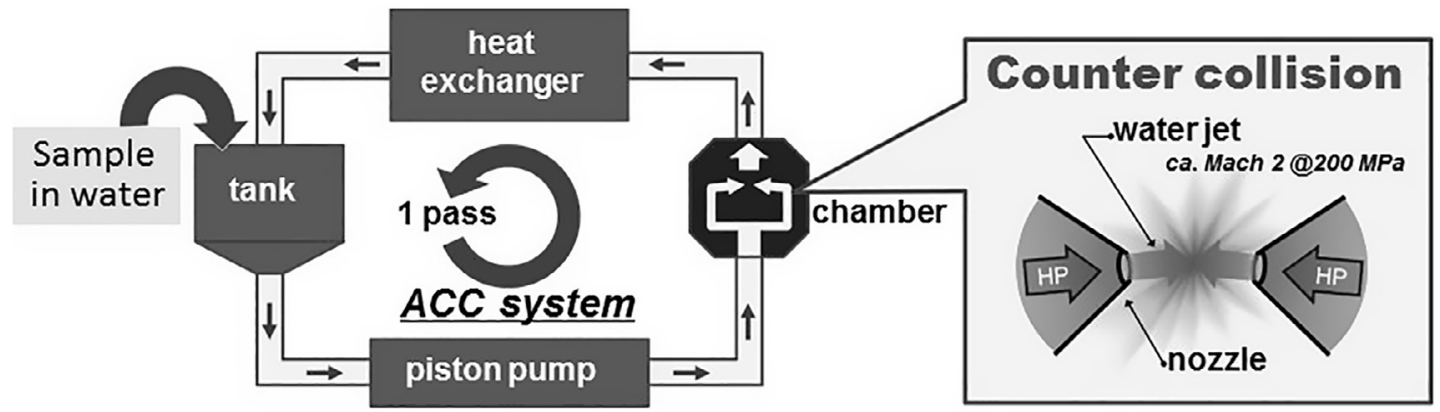

FIGURE 7

Schematic representation of aqueous counter collision (ACC) system using impinging dual aqueous suspension jets.

\section{TABLE 2}

Width, length, and aspect ratio of individual BNC fibers obtained by ACC treatment under $200 \mathrm{MPa}$ as the ejecting pressure.

\begin{tabular}{llll}
\hline Pass number & Width $(\mathbf{n m})$ & Length $(\boldsymbol{\mu m})$ & Aspect ratio $^{*}$ \\
\hline 0 & $69 \pm 35$ & $24 \pm 19$ & 346 \\
20 & $48 \pm 34$ & $5 \pm 4$ & 102 \\
40 & $33 \pm 14$ & $3 \pm 2$ & 101 \\
60 & $34 \pm 13$ & $4 \pm 2$ & 114 \\
80 & $31 \pm 11$ & $3 \pm 2$ & 99 \\
\hline
\end{tabular}

"The aspect ratio was calculated by division of the average length by the average width.

(ii) Surface area measurements $-\mathrm{N}_{2}$ sorption onto the BNC using a surface area analyzer, e.g., Monosorb (Quantachrome Instruments) is used to measure the total surface areas of the fibers. The essential procedure is presented in detail:

- An aqueous suspension containing nanofibers is poured into a test tube which is then quenched in liquid $\mathrm{N}_{2}$ to freeze the aqueous suspension, followed by freeze-drying.

- The dry fibers are kept at $100{ }^{\circ} \mathrm{C}$ for 20 min to evaporate as much as possible water which is bound to the cellulose nanofibers.

- The measurement is carried out at $77 \mathrm{~K}$. The surface areas are estimated from fitting of adsorption data to the Brunauer, Emmett and Teller equation [80]. The specific surface areas of the BNC are obtained by dividing the surface areas with total weight of the nanofibers.

Crystalline structure of a single BNC after ACC [73] - It is well known that BNC secreted by Gluconacetobacter xylinus is a composite of the two crystalline phases, cellulose $\mathrm{I} \alpha$ and $\mathrm{I} \beta(\mathrm{I} \alpha / \mathrm{I} \beta=$ $65 / 35)[81,82]$. FTIR spectra for ACC treated BNC pellicles change depending on Pass number.

The entire spectra indicate that the crystalline structure in secreted BNC is made up of cellulose I. Namely, ACC treatment does not transform it to other cellulose crystalline allomorphs [72], e.g., cellulose II. However, it has been shown that the ratio of cellulose I $\alpha$ to total crystal phases in the native BNC decreases with increasing Pass number. The two typical absorption bands at $3270 \mathrm{~cm}^{-1}$ and $710 \mathrm{~cm}^{-1}$ attributed to cellulose I $\beta$ phase increased, whereas those at $3250 \mathrm{~cm}^{-1}$ and $750 \mathrm{~cm}^{-1}$ attributed to cellulose I $\alpha$ phase decreased with increasing in Pass number $[83,84]$.

In order to quantitatively investigate the ratios of cellulose I $\alpha$ to the total crystalline phases, $\mathrm{CP} / \mathrm{MAS}{ }^{13} \mathrm{C}$ NMR spectroscopy was employed for the samples while systematically changing Pass number. The crystallinity was also measured by X-ray diffraction. The ratio of cellulose I $\alpha$ rapidly decreased from $80 \%$ to $45 \%$ while increasing the Pass number from 0 to 40 , followed by a slow decrease from $45 \%$ to $38 \%$ at 80 Pass. In contrast, cellulose I $\beta$ content increased from $20 \%$ to $55 \%$ in the range of $0-40$ Pass with a further slow increase from $55 \%$ to $62 \%$ at 80 Pass. During the crystalline transformation behavior, the total crystallinity in BNC was not significantly changed and remained constant at ca. 70\% until 80 Pass. These behaviors may be attributed to two explanations:

(i) ACC treatment allows the cellulose I $\alpha$ crystalline phase to be transformed into cellulose $I \beta$, which is supported by a previous report showing that the I $\beta$ phase was thermodynamically more stable than the I $\alpha$ phase [85].

(ii) The transformation from cellulose I $\alpha$ to I $\beta$ occurred on the nanofiber surface. In other words, the shear stress due to the collision energy of water at a high speed in ACC treatment enhanced sliding of cellulose molecules in the cellulose I $\alpha$ phase to be rearranged into cellulose I $\beta$ phase [73], which was induced on the fiber surface.

A previous report by Yamamoto et al. [82] proposed that BNC secreted by $G$. xylinus is composed of a core of I $\beta$-rich domains surrounded by a "skin layer" of cellulose I $\alpha$-rich domains. Therefore, accompanied with the transformation of cellulose I $\alpha$ to I $\beta$ in the skin, proceeded by ACC treatment, the more stable cellulose I $\beta$ phase starts to cover the surface of the BNC. In the ACCtreated BNC, the core of cellulose $\mathrm{I} \beta$ surrounded by $\mathrm{I} \alpha$ is expected to be surrounded by an outer skin of I $\beta$ at the end, resulting in the outer layer protecting the internal cellulose I $\alpha$ from the attack of water jets during the treatment.

The ACC-treated BNC has average dimensions of $35 \mathrm{~nm}$ in width and $4 \mu \mathrm{m}$ in length and exhibits a high specific surface area of about $55 \mathrm{~m}^{2} / \mathrm{g}$ compared to $12-13 \mathrm{~m}^{2} / \mathrm{g}$ for the corresponding BNC network films. Therefore, it is possible that the BNC has a high adsorptivity caused by the large specific surface area. In addition, this new form of nanocellulose is likely to show more resistance against chemical reagents and more insusceptibility to enzymatic degradation caused by a surface covered with stable I $\beta$-rich crystalline phases [86], when compared with the initial microbial cellulose pellicle. It is of interest to compare the high specific surface area values for single BNC fibers with those of CNFs and CNCs (having widths of less than $10 \mathrm{~nm}$ ) 
which are about $200-500 \mathrm{~m}^{2} / \mathrm{g}$. The fact that the unique supramolecular 3D nanostructure is capable of holding a large amount of active ingredients has opened the venue to extensive activities in the development of nanocellulose-based controlled drug delivery systems. Furthermore, it is expected that the single BNC fibers can be applied as building blocks for functional food, fine-patterning structures, coating reagents, and fillers for composites.

\section{BNC medical application}

Surface modification

Surface properties play a vital role in the in vivo performance of biomaterials [87-89]. Wettability, topography, chemistry, surface charge, the presence of hydrophobic and hydrophilic domains, density and conformation of functional groups all play a crucial role in the cell-material interaction [90]. The control of cell adhesion on the polymer substrate, and therefore the ability to guide proliferation, migration, and differentiation is highly desirable and a central issue in the development of scaffolds for tissue engineering [91].

Biomolecule coating - The attachment of cells to biomedical materials can be improved using adhesion molecules, present in the extracellular matrix. A binding site present in many adhesive proteins is the three amino acid sequence arginine-glycineaspartic acid (RGD), which binds integrin receptors on the cell surface [92].

BNC is highly biocompatible in vivo but shows poor cell adhesion [34]. This poor cell adhesion is undesirable in many applications, such as e.g., in the replacement of small blood vessels. In order to sustain cell adhesion to improve blood compatibility, adhesive peptides have been introduced on the BNC surface through different techniques. Bodin and colleagues [93] reported a novel method to activate the BNC surface with the RGD peptide using xyloglucan-GRGDS (XG-GRGDS) conjugates. Cell adsorption studies showed that adhesion of human endothelial cells was enhanced when the BNC hydrogel was modified with XG-GRGDS [94].

The RGD peptide was also used by Andrade et al., in this case the adhesion peptides (RGD or GRGDY) were fused to a carbohydrate binding module with affinity to cellulose (CBM3) [95]. In recent work, Andrade and colleagues [96] studied the blood compatibility of BNC treated with RGD-CBM protein. When endothelial cells were cultured on RGD-treated BNC, a confluent cell layer was formed and almost no platelets adhered to the material. Thus, the improvement of BNC blood compatibility through modification with adhesion peptides seems to be an interesting strategy for the development of BNC vascular grafts.

To enhance the potential use of BNC for vascular tissue engineering scaffolds, Wan and co-workers [97] developed heparinized membranes. In their work, heparin was combined with BNC during the growth of G. xylinus, by adding heparin to the culture medium.

Chemical modification - Also aiming to improve cell adhesion, Watanabe and co-workers [98] chemically modified BNC, with the goal of introducing surface charged groups. In this context, membranes of trimethyl ammonium betahydroxy propyl-BNC (TMAHP-BNC), diethyl aminoethyl-BNC (DEAE-BNC), aminoethyl-BNC (AE-BNC), and carboxymethyl-BNC (CM-
BNC) were produced. No morphological changes were observed in either kind of membrane. The study showed that L929 fibroblast cells grew better on the modified membranes in comparison with the native ones, with TMAHP-BNC membrane being the most suitable scaffold for cell growth.

Trauma and diseases of the bones and joints, frequently damaging both the articular cartilage and the subchondral bone, result in severe pain and disability for millions of people worldwide [99]. In order to mimic the glucosaminoglycans of cartilage tissue in vivo, Svensson et al. [100] added surface charges through phosphorylation and sulfation on BNC matrices. The compressive modulus of the phosphorylated samples increased with the reaction time and improved compared to native BNC. Sulfated-BNC had significantly lower Young's modulus than unmodified BNC, resulting in a reduction of the mechanical integrity. It was verified that BNC support cell ingrowth, and chondrocytes preserved the differentiated phenotype. The described types of chemically functionalized BNC represent some of the first research results that demonstrate an improved interaction of these BNC derivatives with cells. In order to use functionalized BNC for tissue engineering applications, the synthesis methods of these products needs to be optimized.

The modification of surfaces using plasma techniques is becoming increasingly common in biomaterials engineering. The most important advantage of plasma surface modifications is the ability to selectively change the surface properties, without altering the bulk attributes [87]. Pertile et al. [101] modified BNC membranes with nitrogen plasma in order to enhance the cellmaterial interactions through the incorporation of $\mathrm{N}$-groups on the surface. The results showed that different cell lines displayed a different behavior in contact with modified biopolymers. Bhanthumnavin et al. [102] recently reported that BNC surface modification using $\mathrm{O}_{2}$ plasma treatment led to a decrease in the membrane effective pore area and the water flux. The treatment yielded a change of the surface properties and hence a more hydrophilic membrane.

BNC (and other nanocelluloses) are not enzymatically degradable in the human body and as a consequence, biodegradability has become an essential limiting factor in the application of BNC as a scaffold material in tissue engineering. A limited degree of periodate oxidation of polysaccharides may give rise to derivatives with altered chemical and physical properties and most importantly hydrolytic lability. Li and colleagues [103] produced biodegradable 2,3-dialdehyde cellulose BNC by periodate oxidization. While this chemical treatment maintained the original 3D nano-network structure, the obtained scaffold could degrade rapidly in water, phosphate-buffered solution, and simulated body fluids. In another study, Hutchens et al. [104] demonstrated that periodate oxidized BNC retains its original structure and ability to initiate the mineralization of calcium-deficient hydroxyapatite, similar to natural bone apatite. Shim et al. [105] recently reported the one-side modification of a BNC sheet to reactive 2,3-dialdehyde derivatives (DABC), preferentially by limited periodate oxidation.

Surface patterning - A powerful replica molding methodology to transfer on-demand functional topographies to the surface of BNC nanofiber textures was recently introduced by Bottan et al. [106]. With this method, termed guided assembly-based 
biolithography (GAB), a surface-structured polydimethylsiloxane (PDMS) mold is introduced at the gas-liquid interface of a G. xylinus culture. Upon bacterial fermentation, the generated BNC nanofibers are assembled in a three-dimensional network reproducing the geometric shape imposed by the mold. Additionally, GAB yields directional alignment of individual nanofibers and memory of the transferred geometrical features upon dehydration and rehydration of the substrates. The deployment of surface-structured BNC substrates in animal models as skin wound dressings or body implants further proves the high durability and low inflammatory response to the material over a period of 21 days.

\section{In vivo scaffolds}

The need for BNC as in vivo scaffolds covers nearly all surgical fields, from general surgery to neurosurgery to urology. There are mainly two forms of BNC that are suitable for medical implantation: the flat form which is used as a mesh, or a tube for the repair of hollow organs or vessels. The tubular form is especially promising to fill the gap between autologous and alloplastic materials.

Within the urinary tract, defects of the ureter, urinary bladder, and the urethra are in some cases difficult to cure, especially if the defect exceeds a certain size. A direct reconstruction often goes along with strictures, which means scarred constrictions of the uriniferous system. The best results using a BNC scaffold were achieved when the matrix was seeded: Bodin et al. [107] seeded 3 -D porous BNC scaffolds with either human urothelial and smooth muscle cells or with urine-derived stem cells. This led to the formation of a multilayered urothelium and cell-matrix infiltration. Lv et al. [108] used a BNC/gelatin composite scaffold seeded with keratinocytes and muscle cells in a large animal experiment (dogs), whereby the creation of a patent urethra was observed. The use of a 3-D porous BNC scaffold seeded with lingual keratinocytes was recently described by Huang et al. [109]. The 3-D seeded matrix showed significant advantages compared to conventional BNC and un-seeded 3-D BNC in terms of stricture formation. The 3-D scaffold and the seeded matrix were superior in epithelial regeneration three months after implantation.

In vascular or heart surgery, the availability of a patent graft for bypassing a closed vessel is essential. BNC might be a suitable material as it was first described by Klemm et al. [52]. Herein, the use of BNC as carotid interposition graft in a rat model showed encouraging results regarding the patency. Wippermann et al. [110] performed follow-up experiments in a large animal model (domestic pigs), which showed an occlusion of the graft in one pig due to a re-cellularization by endothelial cells. In a subsequent study, BNC grafts were implanted in ten carotid arteries of sheep, but the patency rate was only 50\% in this study. The bursting strength of the grafts far exceeded the physiologic and even pathologic possible blood pressure values of humans [111]. Similar results were reported by Malm et al. [112] and Leitão et al. [113]. Promising results with excellent patency rates were recently published by Li et al. [114], whereby the manufacturing process (rolled membrane) and the follow-up period (21 days) differed significantly from the other mentioned papers.

A duraplasty is often necessary after neurosurgical interventions. In experimental studies, the use of BNC as a duraplasty material was evaluated with excellent results in terms of adhesions, infections, and the general inflammatory response of the host $[115,116]$. Interestingly, a prospective, randomized, multicenter clinical trial in neurosurgical patients showed three and five years before, respectively, comparable results in humans [28]. In comparison to a control group, BNC (in the original publication named "biosynthesized cellulose graft") was proven to be non-inferior compared to commonly used dural replacements. Of course, the histologic evaluation could only be performed in animal experiments, in the human setting, the patency was confirmed by evaluation of the wound healing and radiologic examinations.

Thus, the aforementioned study describing the duraplasty with BNC was an invasive application approach performed in humans. There are some other uses already applied in humans: a Brazilian study [117] continued the promising results of Kim et al. [118] using BNC for tympanic membrane perforation. The special approach of this clinical study was the application in an infectious environment since only patients with tympanic perforations after an otitis media were included. Significant advantages for patients treated with BNC were the possibility of local anesthesia, the significant decreased operation time, and the tremendously reduced costs (as compared with the standard procedure, a temporal fascia graft). Similar results were reported by Biskin et al. [119]. However, even if there is already one randomized trial, the reported patient numbers are still too low to judge BNC for this application.

Another application for BNC already performed in humans is as wound dressings. Beside the treatment of burn wounds, BNC was applied in chronic venous ulcers. There were no infectious complications in the treatment group and, furthermore, less pain and an earlier withdrawal of analgesic medications [120].

Besides all aforementioned usages, BNC is used (experimentally) as a scaffold in bone tissue engineering [121-123], cartilage regeneration [124], laryngeal medialization [125], as a patch for esophageal defect repair [126], and for closure of ventricular septal defects [127], among many others.

Due to the excellent characteristics of the material, it is versatile and applicable and will play a major role in tissue engineering and regenerative medicine in the future.

As mentioned above, there are many medical fields that would benefit from using BNC in humans. However, the market for medical devices is highly competitive. BNC could be utilized in many devices but has to compete with the individual leading product in every application. There are two different modalities: on the one hand the established use of a medical device, e.g., in peripheral vascular surgery where a vascular prosthesis is commonly used, or in hernia repair where a mesh is frequently implanted for the repair of the defect. In such cases, BNC has to be benchmarked against the state of the art and has to prove significant improvements. This process is long lasting and often requires significant funding before a market launch can take place. However, there are completely new fields where the demand for a medical device is evident but has not been achieved yet. This is the case in biliary or esophageal surgery, for example. Here, it is more likely that BNC can quickly close an existing gap between a medical problem and a solution. 


\section{Recent developments in BNC materials}

Food sector - In some applications, BNC shows potential to outperform the currently used celluloses in the food industry as a promising novel hydrocolloid additive. Potential uses of BNC in food technology, as an additive, include pourable and spoonable dressings, sauces, and gravies; frostings and icings; sour cream and cultured dairy products; whipped toppings and aerated desserts, and frozen dairy products. Its use is particularly recommended in situations where low use levels, lack of flavor interactions, foam stabilization, and stability over wide $\mathrm{pH}$ range, temperature, and freeze-thaw conditions are required. The use of BNC in combination with other agents such as sucrose and carboxymethyl-cellulose improves the dispersion of the product. It is also a low-calorie additive, thickener, stabilizer, and texture modifier [128-136].

The technical and dietetic properties of BNC are indisputable, and there is clearly potential for its use in food technology. However, BNC still has not been made available commercially as a bulk product (especially in Western countries), nor has it been translated to actual products as a novel food additive or ingredient. Strong competition with colloidal microcrystalline cellulose and other commercially available cellulose ethers and hydrocolloids makes the viability of such developments further uncertain.

Biomedical sector - Further current developments in the BNC field mainly concern novel carrier materials for cell cultivation $[122,137,138]$, encapsulation of cells/immobilization of enzymes [139], coating of medical devices [140], and the production of BNC materials using the well-known oxygen-transparent silicone supports $[141,142]$. In case of medical implants a lot of results is reported not only in the field of soft tissue implants (see Section In vivo scaffolds) but also regarding materials for bone regeneration $[121,143,144]$.

The native BNC hydrogel is well suited for cell cultivation on its surface. The ingrowth of cells into the bulk is limited by the small size and heterogeneity of the pores. It has been shown that laser-structured BNC hydrogels support ingrowth and differentiation of chondrocytes and have potential as cartilage implants [145]. Another novel bilayer BNC scaffold supports neocartilage formation in vitro and in vivo. Bilayer BNC scaffolds, composed of a dense BNC layer joined with a macroporous composite layer of BNC and alginate, were seeded with human nasoseptal chondrocytes for reconstruction of auricular cartilage. This study demonstrates that bilayer BNC scaffolds offer good mechanical stability and maintain a structural integrity while providing a porous architecture that supports cell ingrowth [124].

3D BNC-alginate composites were engineered by crosslinking homogenized cellulose fibrils using alginate and freeze drying the mixture to obtain a porous structure. In an initial pilot study, the authors compared adipogenic differentiation of mice mesenchymal stem cells on 2D and 3D scaffolds of BNC. The study showed that $3 \mathrm{D}$ culturing of adipocytes in BNC macroporous scaffolds is a promising method for frabrication of adipose tissue as an in vitro model for fabrication of adipose tissue and as an in vitro model for adipose biology and metabolic disease [146].

Park et al. [147] modified the two sides of a BNC membrane asymmetrically with different biomaterials for cell encapsula- tion. One side was modified with collagen for the improvement of cell adhesion and the other side was coated with alginate to protect transplanted cells from immune rejection. Another kind of cell encapsulation was investigated by Khorasani and Shojaosadati [148] as novel protective prebiotic matrices. A suspension of BNC fibers, pectin, and Bacillus coagulans was crosslinked and then coated with starch and carboxymethylcellulose, respectively.

Using an in situ nanocellulose-coating technology based on dynamic bacterial cultures, Zhang et al. [140] upgraded conventional biomedical materials, i.e., medical cotton gauze or other mesh materials. This fabric-reinforced BNC hydrogel was equivalent in gel characteristics of native $\mathrm{BNC}$, and exhibited a qualitative improvement with regard to its mechanical properties.

Technical sector - Especially for technical applications such as fuel cells, (transparent) electrically conductive membranes, and loudspeaker vibration films, there has been extensive R\&D on BNC composites over the past years [10]. Recent results focus on applications in the area of packaging $[149,150]$, water absorption [151] and supercapacitors [152,153], as well as optical devices [154-160]. In such applications, either BNC itself is reinforced by additives [161-164] or BNC serves as the reinforcing material, e.g., for synthetic polymers $[165,166]$. Another aim of current research is the enhancement of BNC properties to get softer and more flexible materials [167].

The pyrolyzation of BNC at temperatures ranging from 800 to $1500{ }^{\circ} \mathrm{C}$ leads to a carbon material with a fibrous structure and a moderately high specific surface area. Kalytta-Mewes et al. [168] tested the use of pyrolyzed BNC as a catalyst support by in situ preparation of nanosized ruthenium clusters. As a preliminary test for the catalytic properties of the material, the low-pressure reduction of carbon monoxide by hydrogen gas was successfully demonstrated.

Recently, Dutta and colleagues published an overview about research activities in cellulose-based energy storage devices [169]. Among the most promising developments highlighted in the review were stretchable $3 \mathrm{D}$ conductive carbon nanofiber networks based on multi-walled carbon nanotubes (MWCNT) incorporated into BNC pellicles, first described by Yoon et al. [170]. One of the latest developments in this very promising field of research are conductive nanocomposite BNC-membranes, which contain polyaniline and highly dispersed graphene (GE) [171]. The authors reported excellent electrochemical performance of the BNC/GE/PANI electrodes and explained their findings with the unique $3 \mathrm{D}$ porous structure and the uniform distribution of GE nanosheets and PANI in the BNC matrix, which makes it especially promising for future flexible energy storage devices.

Over the last decade, BNC has been explored for its use in water purification systems. A patented method describes the preparation of a composite of BNC loaded with a porous adsorbent for flocculation and decolorization of dyeing wastewater [172]. BNC grafted by allylamine and acrylic acid was described as an adsorbent for persistent pollutants containing $\mathrm{Cu}^{2+}, \mathrm{Pb}^{2+}$, $\mathrm{Cd}^{2+}$ and $\mathrm{Cr}(\mathrm{VI})$ [173]. The symbiotic culture of white-rot fungi and aerobic denitrifier bacteria immobilized by bacterial cellulose was reported as suitable for the treatment of mixed wastewater 
composed of dye and domestic sewage. The removal rates proved to be of about $80 \%[174,175]$.

\section{Nanocelluloses from wood}

In this chapter, the focus is on recent developments in the processing and manufacturing of CNFs from wood materials, some new characterization methods and an outlook on the mechanical properties of nanofilms, filaments, and composites. Reference to some earlier reviews can be found in [10,176-178].

\section{Processing and manufacture of CNFs}

Nanocellulose materials from wood are most commonly manufactured from delignified and preferably bleached pulps. The original inventors $[179,180]$ of what was then called microfibrillar cellulose successfully used high-pressure homogenizers for mechanical delamination of the fibers, but recognized that the energy consumption was very high and that extensive clogging of the homogenizers took place, particularly when feeding pulp with a high consistency through the homogenizer.

Since then, several different delamination equipments have been used, such as high pressure homogenizers or microfluidizers, common refiners, ball milling, steam explosion, ultrasonification, high speed blenders etc. and there are many recent reviews on the various mechanical delamination equipments available [181-186]. A serious obstacle has been the low solid content required to avoid clogging in homogenizers/ microfluidizers, and a recent development addressing this is the use of extruders for fiber delamination [187-190] or high consistency milling [191-194]. These methods have the advantage of higher consistency processing, but they seem to be more energy demanding and it is difficult to avoid the presence of larger fragments in the delaminated fiber assembly. Hence, all types of equipment have advantages and disadvantages and it is obvious that the delamination equipment of choice must be tailored to the final end use of the CNFs.

The impediments of the high energy consumption and the clogging tendency of interaction chambers in high pressure homogenizers/microfluidizers have been alleviated by the use of various pre-treatment methods, which have been necessary for commercial exploitation of CNF production.

The pre-treatment methods may be categorized as:

A. Electrostatically induced swelling by charged groups, induced either by pulping or bleaching procedures or by subjecting fibers to oxidative treatments, such as TEMPOoxidation (oxidation by 2,2,6,6-tetramethylpiperidiny loxyl) or cellulose modification by introduction of charged groups, e.g., carboxymethylation.

B. Mild acid or enzymatic treatments.

Electrostatically induced swelling of the cell wall or hydrolysis will decrease cell wall cohesion and alleviate the energy use during delamination. Clogging is related to the susceptibility of fibers to flocculate at the inlet to the interaction chambers.

The native cell wall of wood fibers contains few charged groups, but during pulping, charged groups are introduced when esters are cleaved in the hemicellulose fraction, whereas charges are introduced in the lignin fraction due to disproportionation reactions. It has long been known that the introduced charges will have a strong influence on the cell wall cohesion $[195,196]$, as determined by the swelling behavior of woodbased fibers.

Among the successful pre-treatment methods to decrease the cell wall cohesion are enzymatic treatment [197,198], TEMPOoxidation [177,199] and carboxymethylation [200], but there are a number of emerging technologies, based on increasing the charge of fibers, such as phosphorylation [201], sulfonation [202], periodate-chlorite oxidation [203,204], cationization [205], and carboxymethyl cellulose grafting [206]. Different applications of CNF have different demands particularly with respect to the extent of fiber delamination. In large-scale paper making applications (e.g., as a wet end strength additive), the economics of production is most important and the extent of delamination is not critical, so an enzymatic pretreatment is sufficient to fulfill the demands, whereas in electronic and nanofilter applications, transparency and nanofibril uniformity is critical, demanding an extensive chemical modification. These are examples of low- and high-end applications, respectively.

Whereas fiber charge content by cooking and bleaching is limited to 30-250 $\mu \mathrm{eq} / \mathrm{g}$, the charge content after a second charging treatment can be increased to 300-2000 $\mu \mathrm{eq} / \mathrm{g}$ [207]. As indicated above the charge treatment will drastically decrease the energy required for disintegration as illustrated in Fig. 8 [204].

The charge content is not only important for cell wall cohesion, but has also a significant impact on the extent of fiber flocculation, which controls the clogging tendency of fibers.

The tendency of fibers to flocculate may be understood by the crowding factor concept developed by Kerekes and co-workers [208]. The crowding factor is defined in terms of the number of fibers in a conceived volume and the higher the N-number the higher the susceptibility for fibers to flocculate. The equation reads:

$N=5 C_{\mathrm{m}} L^{2} / \omega$

where $C_{\mathrm{m}}$ is the mass consistency, $L$ is the fiber length, and $\omega$ is the fiber coarseness. This equation is intuitively simple to grasp, as long



\section{FIGURE 8}

The effect of charge content on the estimated energy consumption for desintegration of cellulose fibers into nanofibrils [204]. 
fibers, higher consistency, and lower coarseness increase the tendency of fibers to flocculate.

The friction between fibers is, however, not included in this concept, the impact of which was later realized by Kerekes. The friction between fibers is also controlled by the electrostatic repulsion between fibers and the higher the repulsion, the less surface contact there is and thus the lower the friction will be. The effects of the friction on the rheology of fiber suspensions have also been demonstrated $[209,210]$.

\section{Characterization of CNF materials}

The efficiency of the fiber delamination process may be characterized by a set of different means for morphology studies, such as TEM, field-emission SEM (FE-SEM), atomic force microscopy (AFM), SEM, which are all useful for the determination of width and length distributions of CNFs. Solid state ${ }^{13} \mathrm{C}$ cross polarization magic angle spinning nuclear magnetic resonance (CPMAS NMR) and wide-angle X-ray scattering (WAXS) are also tools for width and crystallinity determinations. Whereas, the width and length distributions of TEMPO-oxidized nanomaterials can be deduced with reasonable accuracy [211], less delaminated CNF materials are much more difficult to analyze.

These examples are all excellent characterization devices, but what are needed are also fast and easy characterization tools that can be used for quality control during industrial manufacturing of CNFs.

Turbidity measurements have been used by many investigators as a fast and rapid tool for the evaluation of CNF quality, and it has recently been shown by a Japanese team [212] that quantitative thickness dimensions can be calculated from turbidity measurements based on the theory of light scattering of thin and long particles, that is from first principles. Fig. 9 [212] shows how the turbidity derived width of fibers fits the AFM-measured thickness for a wide range of CNFs.

Another simple method, centrifugation, has been used by several research teams [213-215] to estimate the fraction of nanomaterial content in CNF preparations. The idea is to disperse the CNFs under conditions of colloidal stability, which usually requires charged systems at a low electrolyte concentration. Fig. 10 [213] shows how the nanofiber yield increases with the carboxyl group content for a series of TEMPO-oxidized samples.

Different groups do, however, not employ the same protocol with respect to gravity or time of centrifugation, and there has not been an independent calibration of the methodology. The solid content during centrifugation is critical as the solid content must be lower than the critical networking concentration [216].

\section{Rheology of CNF materials}

The rheological features and the application of CNF materials in various food applications was first investigated by the inventors of CNF at ITT Rayonier Eastern Division in USA in the late 1970s [180]. As described above, cellulose and its derivatives have been used as emulsifiers and rheological modifiers for a long time in the food industry and cellulose ethers and microcrystalline cellulose made from plant cellulose are widely accepted as approved food additives [217]. As such, the use of CNF in food is not unexpected, and has been found to be an excellent additive for oil/water emulsions and many patents exist on the use

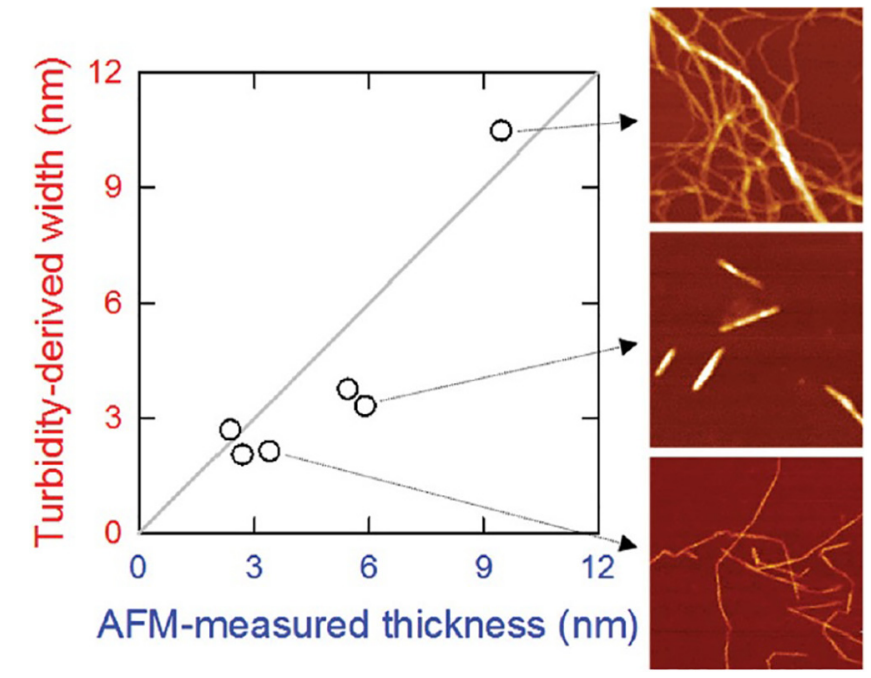

FIGURE 9

Relationship between turbidity-derived width, with the AFM-measured thickness [212].



FIGURE 10

The effect of carboxyl content on the nanofibrils yield using a set of TEMPOoxidized derived catalysts [213].

of CNF in whipped toppings, cake frostings, dressings, gravies, and sauces. The use of vegetable nanocellulose in food applications was also recently reviewed [218].

CNF materials have complex rheology, showing both shearthinning and thixotropic properties, and these rheological properties are useful for the characterization of the materials. There is, however, a lack of universally accepted protocols for this type of characterization, which is a problem when comparing results from different research groups. Additionally many CNF materials are inherently unstable, and require specific protocols $[219,220]$. Hence, Naderi and Lindström [221] stressed that pre-shearing is a pre-requisite for obtaining reproducible results for unstable CNF materials. Nechyporchuk et al. [222] showed the importance of having serrated geometries, instead of smooth geometries as a 
mean of avoiding slip effects. The same group also showed that by combining rheology measurements with visualization devices, shear banding phenomena could be observed at certain shear rates for uncharged systems such as enzymatically treated CNFs. Moreover, by combining rheology with optical coherence spectroscopy [223,224] or ultrasonic speckle velocimetry [225] the instabilities of uncharged CNF materials could also be demonstrated. The latter group compared the behavior of TEMPO-oxidized CNFs and enzymatically treated CNF material, both of which showed complex rheology, typical for the yield stress of non-linear thixotropic fluids. The optical observations revealed that enzymatic CNFs exhibited flocculated textures, which evolved with the applied macroscopic shear rate and sweep history. For the TEMPO-CNF dispersions, the spatiotemporal velocity diagrams were very different from those of enzymatic CNFs. Both velocity fields were heterogenous, but the spatial and temporal variations were much smoother and less erratic for the TEMPO-CNFs compared to the enzymatic CNFs.

The flocculation of CNF systems can be decreased by the addition of polymers, which may have steric stabilizing effects if adsorbed, but may also enhance the viscosity, thus reducing the relative motion of fibers or prevent collisions and contacts between the filaments if the polymer is not adsorbed [226].

In spite of the complex rheology of CNF materials, the rheological properties are useful for the practitioner. The rheological characteristics of CNF materials are strongly dependent on the solid content, usually in an exponential fashion. Typical rheological characteristics are shown in Fig. 11 [227], where the graph to the left, Fig. 11a) shows the shear viscosity versus shear rate of CNF dispersions (carboxymethylated) with different dry contents. To the right, Fig. 11b) shows the power-law evolution of the shear viscosity as a function of CNF consistency [227]. The exponent $(\beta)$ in the power law is 2.0.

As early as 2002, the group of Tatsumi et al. [228] reported an exponential value $(\beta)$ around 2.0 for the evolution of the shear stress versus solid concentration of CNFs for a non-charged system. The same exponent has also been reported for TEMPOoxidized CNFs [229] and for carboxymethyl cellulose grafted CNFs [230]. These results show a strong coherence, in spite of the fact that both non-charged unstable systems and charged stable CNF systems show the same exponent.

The evolution of the storage modulus $\left(G^{\prime}\right)$ is also dependent on the solid content in an exponential manner. Theoretical considerations suggest that for entangled semiflexible polymer systems, the exponential coefficient $(\alpha)$ should be around 2.2 [231], which was exactly what Tatsumi et al. [228] reported. The exponent $\alpha$ in the work by Naderi and Lindström [227] on the rheology of carboxymethylated CNFs was found to be 2.4. There are also reports of higher values such as for enzymatically liberated CNF material [198], where a value around 3.0 was obtained for uncharged CNF material [232]. Naderi [220] speculated that the inclusion of data close to the critical network concentration or incorrect selection of CNF suspensions (in the fitting process) as possible causes for these discrepancies.

Charged CNF systems are obviously sensitive to charge interactions and their rheology is sensitive to electrolytes and $\mathrm{pH}$. Jowkaderis and van de Ven [233] studied the intrinsic viscosity of TEMPO-oxidized CNFs at low solid concentrations and found that the intrinsic viscosity first decreased with the addition of electrolyte. This is due to the compression of the electrostatic double layer, before approaching the intrinsic coagulation threshold, when the viscosity starts to increase again. Similarly, a higher $\mathrm{pH}$ increased the viscosity. Rheological studies have also come to the same results that the viscosity and $\left(\mathrm{G}^{\prime} / \mathrm{G}^{\prime \prime}\right)$ decrease with an increased electrolyte concentration [227]. It has also been found that multivalent cations induce hydrogelation in carboxylated CNF materials, with a higher valency resulting in lower gelation concentration [234].

\section{Outlook on the mechanical properties of CNF nanofilms, filaments, and composites}

The deduction of bulk material properties from fiber/filament properties is generally difficult, particularly for brittle materials, such as CNFs. This is due to the statistical distribution of surface defects, internal stresses etc. The smaller the material entities, the less likely it is to find a defect of given critical size. As CNF materials are far from mature materials, it is understandable that such effects have been given little attention. The importance of such factors is, however, well recognized by the papermaking community in formation of paper sheets, internal stresses, fiber kinks etc.

It is therefore of importance to investigate the maximum strength and stiffness of nanofilms and filaments that have been reported. CNFs have a modulus of around $30 \mathrm{Gpa}$ [235] and an ultimate tensile strength around $1 \mathrm{Gpa}$ [236] at ambient conditions, although there are publications with higher values. In a recent review of CNF film properties Lindström reviewed published nanofilm data [207] and found that the maximum modulus values were between 8 and $11 \mathrm{Gpa}$. If the Cox equation [237] is used $\left(E_{\mathrm{film}}=E_{\mathrm{fibril}} / 3\right)$ the fit between these experimental values is as perfect as it may be.

This approach, however, does not apply to all literature values since it is known that insufficient fiber delamination or the absence of appropriate pre-treatments before delamination will invariably lead to inferior mechanical properties of nanofilms. Likewise, a chemical or mechanical pre-treatment of fibers, which decreases the DP below a threshold value or the choice of a low DP material, will be out of the scope of this analysis.

It is well recognized that nanofilms share many features similar to paper structures, albeit at different structural levels. Historically, the Page equation [238] was the golden standard for paper strength theories, but suffered from the fact that it was extremely difficult to obtain accurate measurements of the fiber-fiber bond strength. As the shear strength can be measured with excellent accuracy, the validity of the Page equation has now also been verified from first principles [239]. The Page theoretical framework has now also been extended to nanopapers [207] and by extrapolation of the surface area to zero, the Page equation predicts a value of $172 \mathrm{Nm} / \mathrm{g}(\approx 260 \mathrm{Mpa})$. This also equals the short span strength of a paper made from the fibers that the nanopaper was made from. It is, however, important to understand that well-delaminated CNF films are non-porous and that the density is equal to the density of cellulose $[177,240]$, otherwise, this extrapolation cannot be done. The reviewed literature values points to a maximum tensile strength generally ranging from $165-185 \mathrm{Nm} / \mathrm{g}(\approx 250-280 \mathrm{Mpa})$ which is in good agreement 

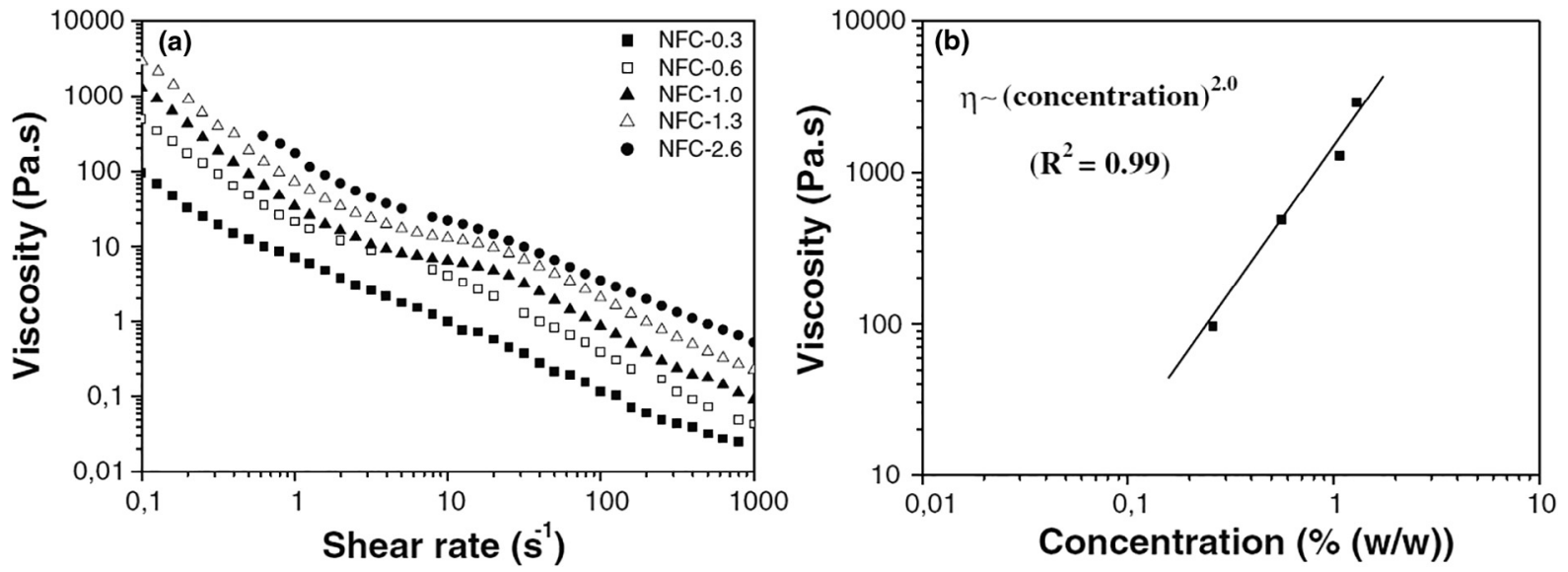

FIGURE 11

(a) Shear viscosity versus shear rate of CNF dispersions with different dry contents. (b) The power-law evolution of the shear viscosity as a function of nanocellulose consistency [227].

with the theoretical prediction. Enzymaticallytreated, carboxymethylated and TEMPO-oxidized cellulose all have maximum tensile strength properties in this range. Hence, there is no influence of the pre-treatment procedure if the CNF materials are sufficiently delaminated or if the CNFs are treated in a fashion to yield very low degrees of polymerization. It is not entirely correct to use the Fox scaling model for tensile properties, but if used, these experimental values are not too far from $1 \mathrm{Gpa}$.

For some time attempts have been made to wet-spin CNF materials [241-243].This is a particularly challenging exercise due to the low solid contents during spinning and the presence of fiber fragments inducing filament defects. Of particular interest has been the development of a completely new flow focusing spinning technology [243], with which a very high alignment of the nanofibrils can be obtained. Using a carboxymethylated CNF dispersion, the same group has been able to reach a CNF modulus of $53 \mathrm{Gpa}$ and a tensile strength of $830 \mathrm{Mpa}$ [244], which is quite close to the suggested strength of nanofibrils at $1 \mathrm{Gpa}$.

From the referred papers, the outlook is that property predictions of CNF films and filaments can be made from some fairly simple considerations and can be experimentally verified.

In spite of being strong, these CNF films and filaments still have deficits (e.g., water removal, economics, etc.) for large-scale manufacturing and they are brittle materials.

CNF films and filaments have a fairly low strain to failure, usually in the range between 3 and $8 \%$. Moisture is an efficient plasticizer for cellulose, but the tensile strength drops significantly with increased humidity and nanocellulose films lose their integrity at high moisture contents [245]. The sensitivity of CNF materials to water can, however, be much improved by cross-linking with multivalent cations, provided that there is a sufficient amount of charges on the CNFs [246].

If nanopapers are compared to common paper materials, there are several ways to enhance the strain to failure for paper. The strain to failure for paper increases with an increased shrinkage of the paper. The shrinkage on a fiber scale is governed by the transversal shrinkage of the fibers leading to fiber microcompressions, which is governed by the fiber swelling $[247,248]$. As cellulose with a high crystallinity does not swell in a significant manner, this mechanism is not available for the consolidation of nanopapers. Instead, alternative routes must be explored, such as composite formulations.

The current interest in nanocomposites is soaring, and the same goes for CNF composites. There is an extensive number of reviews in the area of CNFs (and nanocelluloses, more generally) many of which come from the Dufresne group [249-254]. Scientists agree with the notion that one great challenge with CNF composites is the dispersion of the CNF filaments in the matrix, particularly for olefinic matrix materials. As it is also known that the mechanism for reinforcement is percolation and as dispersion usually requires some kind of dispersant, the interaction between the reinforcing filaments is being blocked. Hence, dispersion may contradict the percolation ability.

To date, most success has been achieved using polysaccharides to enhance the toughness of nanofilms [255,256]. In an interesting approach by the group of Walther [257], matrix materials were studied based on a series of non-ionic polymers with various $T_{\mathrm{g}}$ values. They found that an optimum toughness of the composite was obtained when the $T_{\mathrm{g}}$ of the matrix was equal to the service temperature. This may serve as an interesting guideline for future studies of cellulose-based nanocomposite materials.

In general $\mathrm{BNC}$ would be superior to $\mathrm{CNF}$ from a reinforcement perspective. This is because BNC is stronger than CNF due to its wider, longer, and more crystalline microfibrils and CNF materials often have weak links due to harsh processing. The processing of BNC may, however, be very problematic in many composite applications because of the dispersion problems associated with long strands, unless they are cut into shorter sizes. There has, however, to our knowledge not been any successful report on the dispersion of $\mathrm{BNC}$ in engineering composite materials.

There is a broad palette of engineering applications of CNF materials including composite materials for the automotive, building (cement and plastic reinforcement), packaging (coatings, films, paper and filler reinforcement) sector, air and water filtration. Reinforcement of paper/board can be considered as the most mature sector. Many applications have been listed in 
publications by the United States Department of Agriculture's Forest Service, Forest Products Laboratory Lab., Madison, Wi, USA [258,259].

Although this review cannot cover all different applications of CNF materials, the reader should be aware of that there are considerable recent research efforts in the fields of energy harvesting, electronic applications, and water purification efforts, as described above for BNC. These efforts are driven by environmental issues related to greenhouse gas emissions, embodied energy, toxicity, and the fact that sustainability of materials are becoming much more important to our society.

In the energy field [260], the focus is on energy storage devices such as lithium ion batteries, supercapacitors, and solar cells [261,262] The combination of low surface roughness, transparency, low thermal expansion, and strong mechanical properties are desirable in CNF materials making them suitable for various electronic smart materials, sensors, and various electronic devices in printed electronics [263].

It has been recognized that CNF materials have a greatuntapped potential in various water treatment technologies. This is basically due to their high specific surface area, high strength and ease of functionalization and environmental friendliness. CNF has been used in various nano remediation technologies, such as contaminant adsorbents for metal ions, scaffolds, and membranes for water filtration [264-266]. Progress has been made in the manufacture of thin-film nanofibrous composite membranes, where CNF is employed as the top layer in asymmetric composite structures [267]. A highlight recently was a concept with directed water-channels, which was found to be a key to achieving high water permeability without sacrificing rejection [268]. Another interesting field is the finding of the anomalous scaling law of strength and toughness of cellulose nanopaper. Surprisingly, both the strength and toughness of cellulose nanopaper increase simultaneously as the size of the constituent cellulose fibers decreases: the smaller, the stronger, and the tougher [269].

\section{Cellulose nanocrystals: the whisker-like nanocellulose} General production routes and sources of CNCS

The isolation of cellulose nanocrystals (CNCs) from wood pulp and cotton via acid hydrolysis was first reported in the 1940s and the particles were termed crystallites and cellulose micelles [270-272]. Since then, these colloidal "whisker-like" particles (Fig. 12) have been thoroughly studied and their industrial production scaled up, paving the way for commercial products to fill both commodity and niche applications. Many excellent review articles [11,178,273,274] and books [249,275] on CNCs have been published and the scientific and patent literature continues to grow exponentially (Fig. 13).

$\mathrm{CNCs}$ are considered an emerging nanomaterial based on their commercial production [276] and their potential to solve new and existing materials problems. New ISO, TAPPI, and CSA Standards on CNCs are being developed and published, further highlighting the market interest [27,277]. Many of the potential "nano-enabled" CNC materials have yet to be envisioned in their entirety and it is this need for innovation as well as fundamental science that has captured the imagination of aca- demics and industry alike. Compared with other nanocelluloses, CNCs stand out due to their rigid structure, strength, amphiphilic nature, chemical purity, optical properties, ability to be completely redispersed from dried powder [278] and perhaps above all, the fact that they can be uniformly and reproducibly produced (as shown through recent benchmarking studies [279]). Additionally, CNC suspensions are "all nano" - CNCs from most plant sources have cross-sections of 5-10 nm and lengths of 100$200 \mathrm{~nm}$ [11] and while polydispersity is expected for particles derived from natural materials, the size distribution is narrow compared to the mixtures of nano and micro fibrils found in CNFs or the mats/fibril bundles produced by bacteria.

Sulfuric acid is the most commonly used acid for the isolation of CNCs and grafts sulfate half ester groups on the CNC surface, imparting a negative surface charge and colloidal stability in water [280]. This colloidal stability is noteworthy as it allows for easy processing in water without the need to dissolve cellulose (which requires uncommon solvents [281]) or chemical derivatization. The charged surface groups are grafted through the one-step hydrolysis process as opposed to $\mathrm{CNF}$, which needs separate chemical treatment steps to achieve similar surface charge densities (i.e., $100-400 \mathrm{mmol} / \mathrm{kg}$ ). The sulfuric acid hydrolysis process has been optimized extensively in the literature [25,282-286]; acid concentration, hydrolysis time, and temperature have the most significant effects on $\mathrm{CNC}$ properties and yield. Slight changes in hydrolysis temperature have furthermore been shown to affect surface bound oligosaccharides which affect CNC rheology and liquid crystalline tendencies [287]. While it is well understood that acid preferentially degrades more accessible/disordered cellulose leaving the highly crystalline CNC whiskers intact, there remains debate about the distribution



FIGURE 12

Tapping mode AFM height image showing the whisker-like shape of cellulose nanocrystals extracted from wood pulp via sulfuric acid hydrolysis. CNCs were spin coated onto a silicon wafer substrate. 


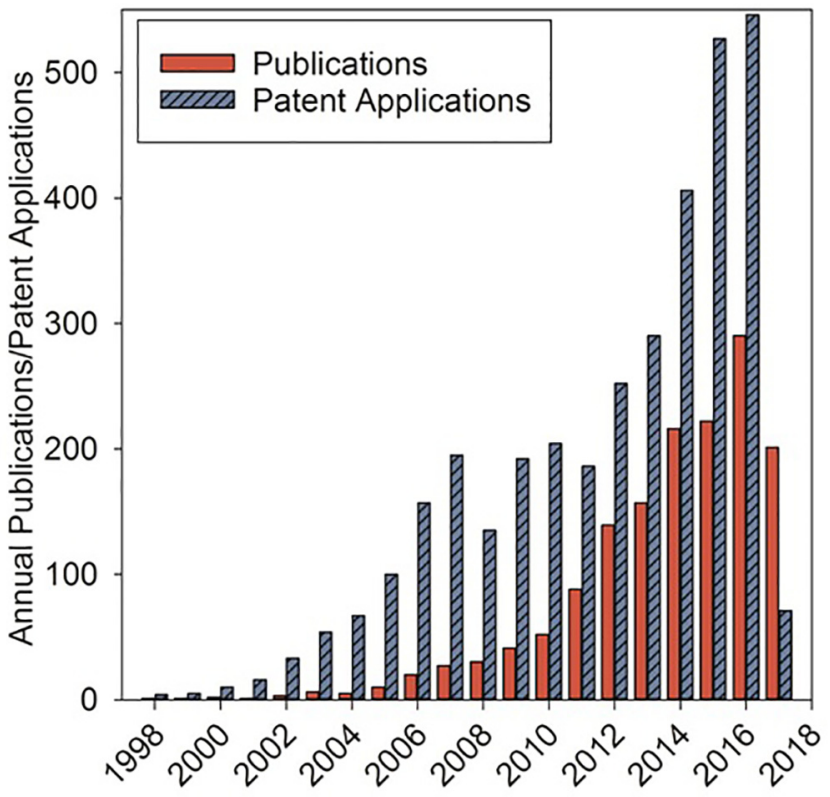

FIGURE 13

Annual cellulose nanocrystal publications (red) and patent applications (blue stripes) from 1998 to 2017 (compiled August 2017). Publication and patent searches were conducted using Web of Science and Patsnap databases, respectively, using the synonyms: cellulose nanocrystal, cellulose nanowhisker, and nanocrystalline cellulose.

of ordered and disordered cellulose domains [21]. Importantly, the industrial production of CNCs is a relatively green process, as the starting material is renewable, the acid can be recycled, and the degraded sugars may be separated for biofuel production.

Newer methods to isolate CNCs include oxidation [288] and hydrolysis with other acids such as hydrochloric [289], hydrobromic [290], citric [291], phosphoric [292], oxalic, and maleic acid [293]. The choice of acid directly affects the colloidal and thermal stability, size, and surface charge of the CNCs. For example, phosphoric and hydrochloric acid hydrolyses yield CNCs with low or no charge content and the CNCs are typically aggregated but have higher thermal stability [292]. It is therefore important to optimize reaction conditions for each isolation procedure in order to ensure that stable and predictable nanomaterials are prepared.

The most common feedstocks for CNCs are wood pulp and cotton [282], however, other sources such as algae [294], bacteria [295], and tunicate [296] may be used. Cellulose source affects dimensions, surface activity, and self-assembly properties, therefore a thorough characterization of CNC starting material is recommended. Recently, new sources of CNCs have been reported including pineapple [297], coconut husk [298], bamboo [299], rice husk [300], banana pseudostems [301], and Miscanthus $x$. Giganteus plants [302], whereby producing CNCs from fast-growing crops and agricultural waste may improve their carbon footprint even further.

\section{CNC properties and performance}

Like other nanocelluloses, CNCs have an abundance of hydroxyl groups on their surface that are amenable to surface modification. Polymer grafting, small molecule functionalization, and adsorption may be used to alter their chemical functionality/compatibility, colloidal stability, responsive behavior, and hydrogen bonding capacity [303]. A general overview of common surface modification reactions for CNCs is shown in Fig. 14 [304]. For example, CNCs with responsive polymers have been demonstrated as flocculating agents [305-307] and emulsion stabilizers/breakers [308] and the potential for other water treatment technologies with CNCs has recently been reviewed [264]. Additionally, CNCs as supports for catalysts [309], antimicrobial agents [310], and metal and luminescent nanoparticles [311-314] is another quickly growing topic in the literature. Interestingly, CNCs are amphiphilic due to the polymer chain packing in their crystalline structure [315] which results in a hydrophobic edge void of hydroxyl groups. This makes CNCs ideal as Pickering stabilizers in emulsions; oil-in-water [316], water-in-oil [317], double [318] and water-in-water emulsions [319], emulsion gels [320], dried oil powders [321], emulsion polymerized latexes [322,323] and aqueous foams [324] have recently been reported. As such, both the inherent chemical properties of CNCs and the ease of chemical modification contribute to the large range of anticipated applications.

The diameter and length (and therefore the aspect ratio) of CNCs are smaller than other nanocelluloses. This affects their rheological [325] and interface stabilizing behaviors [326], packing density [327], and mechanical reinforcement abilities [328]. So while CNCs are better at reproducibly controlling rheology or stabilizing emulsions compared to other nanocelluloses, they are inferior in gel and composite applications (or at least more material is needed to obtain similar results to CNFs, for example). CNCs form a gel at much higher concentrations than other nanocelluloses since they lack the length and flexibility needed to entangle [329], and the percolation threshold to reinforce composites is significantly higher than for higher aspect ratio particles [178]. To overcome the short aspect ratio of CNCs, researchers have recently looked at crosslinking $\mathrm{CNCs}$ to form "stable entanglements" [330] as well as optimizing hydrolysis conditions to produce higher aspect ratio nanoparticles, with 30 being the highest aspect ratio reported for sulfuric acid hydrolyzed CNCs [282].

The optical birefringence and tendency for CNCs to form lyotropic chiral nematic liquid crystals, which offer bright iridescent materials when dried, suggests potential applications in security papers, pigments and biosensors (Fig. 15a and b) [331]. Gray and coworkers have extensively studied the effect of CNC properties on their ability to self-assemble [332-334]; while most colloidally stable CNCs will adopt this helicoidal structure, the pitch and resulting optical properties are highly tailorable [331]. The iridescence of dried CNC films has spurred research thrusts around the world with the most notable work by MacLachlan and coworkers who used CNC films to template a new family of functional chiral organic, inorganic, conductive, mesoporous and hydrogelbased materials, such as those shown in Fig. 15c [335,336]. Additionally, the drying of confined liquid crystalline droplets of CNCs has provided significant physical insight into nanoparticle self-assembly phenomena [337-340].

The rigid, crystalline nature of CNCs results in a nanoparticle with a specific Young's modulus similar to Kevlar ${ }^{\circledR}$ and steel $[178,274]$. This mechanical strength arises from the high degree 

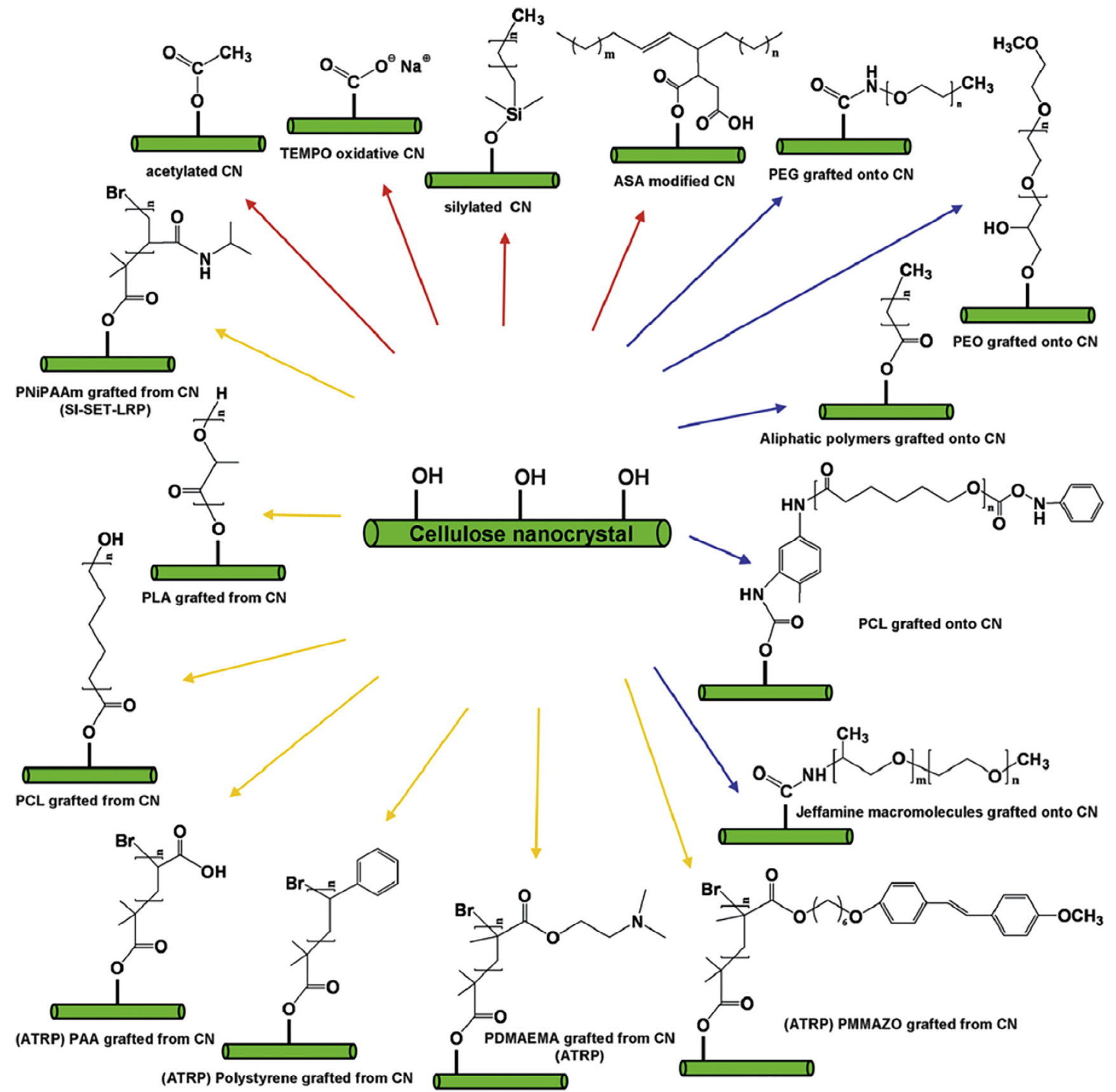

\section{FIGURE 14}

Schematic showing common surface modification reactions of cellulose nanocrystals (termed "CN" in the figure). Reproduced from Ref. [304] with permission from RSC Publishing.

of order and intermolecular hydrogen bonding between cellulose chains [251]. While past work has failed to fully exploit the mechanical strength of CNCs (and other nanocelluloses) in composites, recent examples have approached the theoretical limits. Some advances have come through better processing routes, as well as improved compatibility of hydrophilic CNCs with generally hydrophobic matrices: examples with notable mechanical/ performance enhancements include polymer nanocomposites/ membranes with modified CNCs [341-344] and cements where CNCs are colloidally stable prior to their incorporation due to the processing which takes place in water $[345,346]$.
The molecular order within CNC particles not only gives them high mechanical strength but also imparts a giant permanent electric dipole moment [347] and a significant diamagnetic susceptibility [348]. Based on this, assembly of ordered CNC materials is readily achievable, often over short time periods and using weak electromagnetic fields, i.e., perfect orientation in under $200 \mathrm{~min}$ in a $0.5 \mathrm{~T}$ magnetic field [349-351]. This opens new possibilities for aligned composites, materials with directionally dependent physical properties, and for example, aligned scaffolds that may direct cell growth in tissue engineering applications [352-354]. Although CNCs themselves are 


\section{(b) Optical properties}

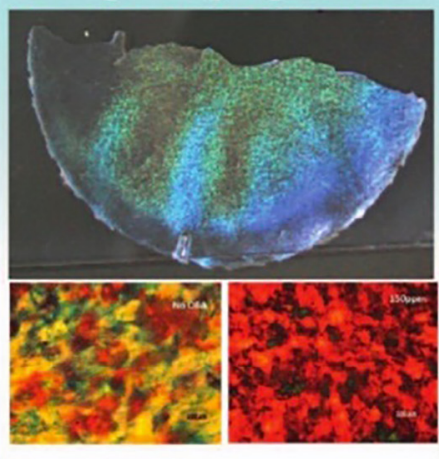

(a) CNC suspension

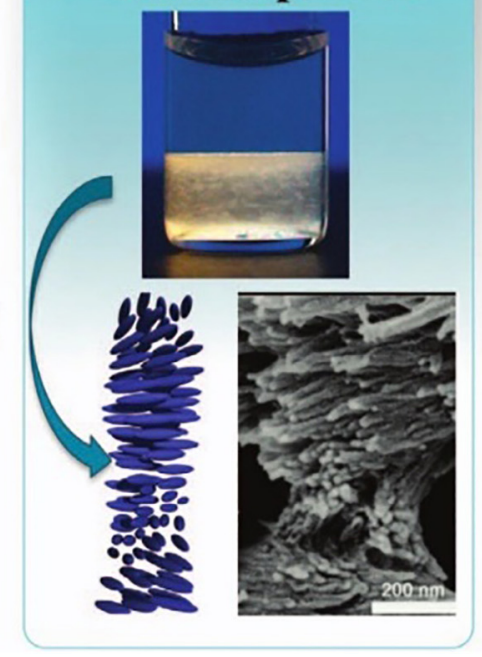

(c)

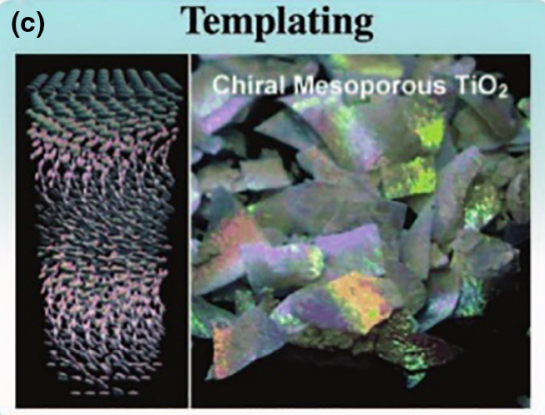

FIGURE 15

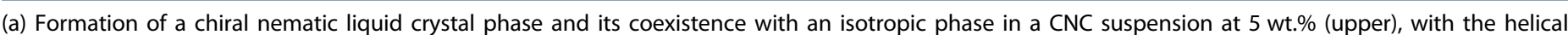

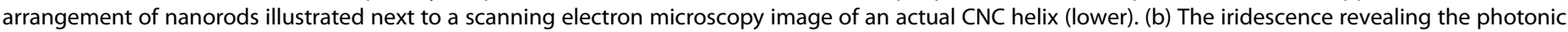

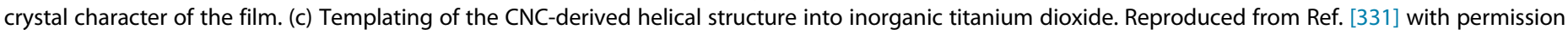
from Nature Publishing Group.

non-conductive, considerable work combining them with conductive/capacitive polymers and nanoparticles, or carbonizing them to induce conductivity has led to a range of flexible energy storage devices and sensors and is a research area that continues to grow [355-357].

\section{Upcoming industrial applications for CNCS}

While many of the applications described above remain at the bench scale, the current industrial production of sulfuric acid hydrolyzed CNCs by CelluForce, the USDA's Forest Products Lab, Melodea/Holmen, InnoTech Alberta, FPInnovations and Cellulose Lab (in order of highest to lowest approximate production capacity) shows promise for the widespread use of CNCs in commercial applications. At the 2017 TAPPI Nanotechnology conference in Montreal, Canada many researchers, producers, and end users gathered to discuss the state of the art in nanocellulose advancements. In a panel discussion, end users highlighted the properties that make CNCs unique compared to other nanomaterials like silica, carbon black and clays: size and chemical uniformity, lightweight, large-scale availability and product uniformity, simple incorporation (i.e., surface modification for many applications is unnecessary), additionally CNCs can be added incrementally or as hybrid solutions in existing products. Some of the emergent industrial applications are summarized below. Notably, many of these applications remain at small scales, however a few emerging products have moved into field or product testing.

Oil and gas - The use of CNCs in the oil and gas industry may include cements, stimulation, drilling, completion and spacer fluids where CNCs could act as stabilizers, thickeners, shear thinning agents, proppants, or reinforcing agents. Results from the first large (i.e., ton scale) industrial testing of a CNC product was recently presented by Schlumberger at the TAPPI Nano conference [358]. The promising report showed that using CNCs in conventional gravel pack fluids prevented the settling of said fluids due to interactions between the CNCs and surfactants present [358]. The thermal stability of CNCs and their rheological properties are key aspects for their use in oil and gas applications and are being extensively studied [359-361].

Cosmetics, pharmaceutical, food, packaging, environmental and biomedical applications - The interface stabilizing ability, chemical inertness, and non-toxicity extend the potential of CNCs to cosmetic, pharmaceutical, and food grade formulated products, although further regulatory testing is still necessary. Demonstrated biomedical applications include drug delivery, tissue engineering, biosensors, and bioadhesives [310,362]. Contrary to BNC, CNCs are not "pure" cellulose - they contain surface sulfate half ester groups that make up $<1 \%$ of CNCs by mass and impart important properties such as colloidal stability and functional handles for chemical modification. Despite this difference, a recent review by Roman [362] summarizes the non-toxicity of sulfated CNCs in all studies shown to date.

Recent investigations have reported details of the nontoxicity of CNCs in different cytotoxicity and hemotoxicity testings. The excellent biocompatibility might be related to the negative surface charge of the CNCs which hinders the binding between CNCs and cell membranes due to electrostatic repulsion [363]. This cell compatibility contrasts other elongated, rod- or tube-like nanomaterials such as silica or carbon nanotubes [364,365]. To simulate the in vivo situation more closely, CNCs were additionally tested in an ex ovo shell-less hen's egg model [366] to study their biocompatibility after local and systemic administration and did not reveal any disturbances of the eggs [367]. The systematic study showed independence regarding the (i) hydrolysis temperature, (ii) sulfuric acid concentration, (iii) hydrolysis time, 
(iv) origin of the material or even the (v) degradation technique.

Despite the biocompatibility studies cited here, cell uptake and interactions in the body are strongly governed by details like surface charge and chemistry [368,369], and further in vivo research and bioaccumulation studies are likely needed before CNCs can be considered safe for some of the anticipated medical, food and cosmetic applications. Importantly, CNC production is considered safe (placing CNCs on the "nontoxic" domestic substance list in Canada, by Environment Canada), inhaled spray-dried CNC powders have not shown negative effects on the lungs [370,371], and ecotoxicological characterization shows CNCs have low toxicity potential and environmental risk [372].

To date, many examples of CNCs in gels/foams/aerogels [329], microencapsulation [321,373], and emulsions (described above) have been reported. Envisioned food applications are similar to the already in-place use of cellulose derivatives and microcrystalline cellulose, where the CNC advantage is high specific surface area and their whisker shape. More specifically, CNCs have been proposed as food stabilizers [374], agents to protect or carry scents and flavors [321,375,376] and as food coatings/ edible films [377-379] but to date no work has shown their commercial use or approval in food grade products. Some more traditional paper/board coating and reinforcement applications, as well as packaging applications, are also projected for CNCs where biodegradable (and "smart") food packaging seems particularly promising [380].

In recent years, CNCs have been explored for their use in water purification systems such as hydrogel beads for the removal of aqueous dyes [381], water filtration membranes [382-384], nanocomposite heavy metal sensors and absorbents [385,386], aerogels [387], flocculants, and nanocomposite filters for groundwater mediation [388]. A recent comprehensive review covers the use of nanocelluloses in water treatment technologies [264].

Finally, CNCs are expected to find use in cosmetic products such as lotions, soaps, hair treatments and anti-drip and colorenhancing agents, as discussed at conferences and seen in the patent literature. Cosmetic companies including L'Oréal have shown interest in these biocompatible, biodegradable and biobased nanomaterials.

Paints, adhesives, coatings, and composites - Again, the stabilizing and reinforcing abilities of CNCs promise to enhance latexbased applications such as paints, adhesives, and coatings and make their production processes more environmentally friendly (e.g., by replacing solvent-based polymerization methods and/or components like synthetic surfactants). Simply mixing CNCs and synthetic latexes (or in situ polymerization) can dramatically improve properties such as mechanical strength [389], shear/peel strength and tack $[323,390]$ and $3 \mathrm{M}$ was the first company to patent the use of CNCs in pressure sensitive adhesives (PSAs) Fig. 16 highlights the improvement in all performance metrics for a butyl acrylate/methyl methacrylate latex-based PSA with CNCs: increasing the CNC loading increases shear, tack and peel and adhesives synthesized in the presence of CNCs outperform the latex/CNC blends, possibly due to crosslinking and improved film formation [390].
A commercial wood-based adhesive containing CNCs is already on the market, and the use of CNCs as adhesives themselves has been shown [391]. Other highly investigated coating systems with CNCs include both solvent and waterborne latexes and epoxies such as polyurethanes, acrylics, polyvinyl alcohol and elastomers [392-394]. Patents in this area are quickly increasing [379] highlighting the potential of protective, hydrophobic and functional coatings [395], for example, using modified CNCs or photocurable resin/CNC blends for wood and other substrate protection [396-398].

The rigid nature of CNCs also allows for their use in composite fiber applications. The most commonly reported method for producing $\mathrm{CNC}$ reinforced fibers is by electrospinning. Polymers such as poly(acylic acid) [399], poly(ethylene oxide)[400], and poly(lactic acid) [401] have been combined with CNCs to prepare fibers with improved mechanical strength. Lignin-CNC composite fibers [402] and all cellulose fibers [403] have also been prepared and show promise as "all green" materials. Furthermore, incorporating CNCs into automotive parts (plastic and foam composites) is feasible given that other bio-based components and fibers have already been adapted where light-weighting is a top priority, by companies like Woodbridge and Ford. Companies such as 3M, Avery-Dennison, BASF, Cabot Corporation, Dow, Nike, and Xerox have expressed interest in incorporating CNCs into their existing and future products.

\section{Nano-scale drug carriers using nanocellulose}

The nanocellulose market was predicted to register a market size with a value of $\$ 250$ million by 2019 [404]. In line with this, the number of scientific reports about nanocellulose in medical and pharmaceutical applications has steadily increased over the last ten years. In this chapter, the focus is placed on drug carriers based on nanocellulose. But even more, there are further investigations on the enabling of different bioactive functionalities and interactions including cell cultivation media and anti bacterial as well as anti-viral effects of functional nanocelluloses [405-407].

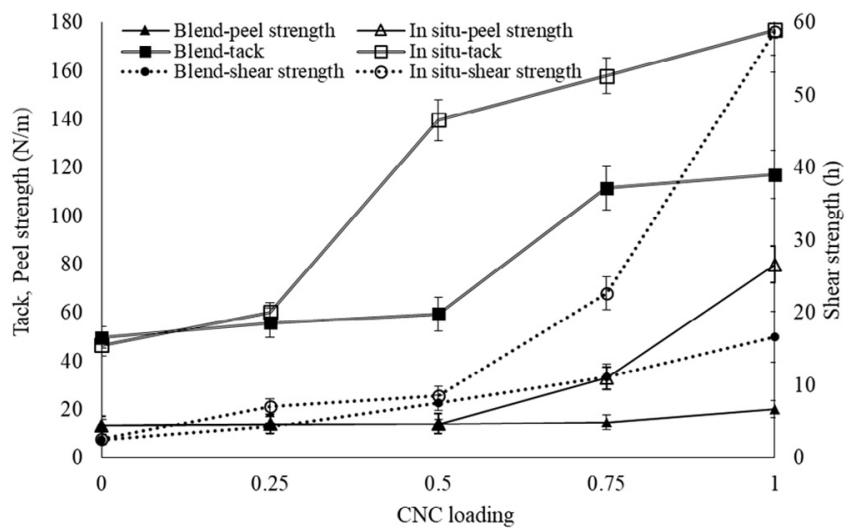

\section{FIGURE 16}

Shear strength, tack, and peel strength increase with CNC loading in poly (butyl acrylate/methyl methacrylate) pressure sensitive adhesives prepared by emulsion polymerization. Closed symbols represented blended latex + CNC systems, while open symbols refer to samples produced with CNCs in situ during emulsion polymerization. Reproduced from Ref. [390] with permission from Elsevier. 
In addition, chemical grafting (such as those shown above in Fig. 14) in aqueous conditions opens up the possibility to modify nanocelluloses [408]. Nevertheless, the number of products in the medical and pharmaceutical field that make it to the market is still low, and this is attributed to challenges such as the formulation of highly lipophilic or high molar mass drugs, the time and spatial control of especially long-term drug release and the limited up-scale of production to large batches.

In the field of drug formulation, the success story of nano- and micro-celluloses started when they were demonstrated as effective excipients including tablet binders and fillers, film coatings, or as tablet matrices. For example BNC powder showed a higher bulk density, better flowability, easy fragmentation of particles and rearrangement at a lower compression load, less elastic recovery and a higher tensile strength and overall improved the processability in tablet and capsule formulations compared to microcrystalline cellulose (e.g., Avicel ${ }^{\circledR} 101$ ) [409]. The quality of BNC films intended for the coating of solid dosage forms was found to be comparable to commercial products with regard to tensile strength, elongation and elasticity modulus [410].

The fact that the unique supramolecular 3D nanostructure is capable of holding a large amount of active ingredients, has opened the venue to extensive activities in the development of nanocellulose-based controlled drug delivery systems. In particular the renewability, facile derivatization, high biocompatibility as well as the animal- and human free origin render nanocellulose highly attractive as a drug carrier [10]. Although the number of basic research reports is still growing, there are only a few nanocellulose-based carriers containing active ingredients in late stage clinical trials or even on the market.

Three categories of nanocellulose materials have been described as drug carriers: planar hydrogels (fleeces, films, membranes, coatings) [410-413], CNFs $[414,415]$ as well as CNCs [416-419], with the two latter preferentially formulated as nano- and microparticles, gels, or suspensions [9]. For the entrapment of drugs these materials were used in the wet native [37,420,421], dried (freeze-dried, critical point dried) [422] or semi-dried $[413,423]$ form, as well as air-dried materials with a shape memory effect $[29,424]$. After freeze-drying of BNC uptake and release of drugs (e.g., albumin) were found to be reduced due to changes of the fiber network [425], which is why often semidried matrices were preferred.

The drug loading strategies for nanocelluloses preferentially encompassed loading techniques after the production of the material ("post synthesis loading") based on static or agitated adsorption [37,426], boiling [427], coating [428] as well as soaking techniques for semi-dried and dried nanocellulose [413,429], as they are easy to perform under mild conditions without impairment of drug stability or efficacy. High-speed loading techniques accomplishing drug incorporation within about $15 \mathrm{~min}$ (soaking, vortexing) were preferred for drugs with low stabilities compared to adsorption techniques that take $24-48 \mathrm{~h}$ as well as for industrial time-effective settings. Drug entrapping strategies for CNFs or CNCs are, for example, performed by spraying [415], crosslinking [419,430], concurrent drying [414], or electrostatic interactions with or without previous surface modification [431-433]. Typical drug release profiles of BNC, CNFs, or CNCs are characterized by a biphasic trend with a fast initial burst release in the first few hours $(0.5-10 \mathrm{~h})$ followed by a slower release phase up to $72 \mathrm{~h}$ (Fig. 17), and based on the Fickian diffusion law or the Peppas' semi-empirical power law equation which demonstrates the overlay of diffusion and swelling [418-420, $427,434-436]$. The majority of papers report biphasic release profiles mostly for water-soluble drugs and small molecules, but also macromolecular drugs or peptides and proteins can be incorporated in BNC, CNFs, or CNCs (see Table 3).

Larger hydrophilic drugs such as povidone-iodine demonstrated a delayed release out of BNC mostly due to the high molar mass of the drug [411]. As an example of small-sized drugs, in the fast initial release phase over $8 \mathrm{~h}$ only about $46 \%$ povidoneiodine compared to $67 \%$ polyhexanide were released. Furthermore, polyhexanide reached equilibrium conditions after $24 \mathrm{~h}$ whereas povidone-iodine showed comparable values only after longer release times of $48 \mathrm{~h}$.

Still challenging is the controlled release of highly lipophilic drugs due to their incompatibility with the hydrophilic character of the nanocelluloses [412,426,432]. Cetyl trimethylammonium bromide-coated CNCs bound significant quantities of the hydrophobic drugs docetaxel, paclitaxel, and etoposide followed by about $20-26 \%$ release in the first hours and a longer release period of 2-4 days [432]. Alternative approaches favored the covalent binding of drugs to CNCs [444,445], but BNC was also covalently grafted with RGDC peptide by 3aminopropyltriethoxysilane followed by covalent binding of gentamycin to improve interactions with cells as well as antimicrobial properties [446].

To overcome the typical release profiles described above, nanocelluloses have been functionalized either through chemical modification or physical incorporation and blending such as coatings/shells, fillers, or matrices to strengthen drug binding, increase stability, or prolong drug release $[447,448]$ and to expand the portfolio of applicable drugs. "Smart" nanocelluloses were reported to react to environmental stimuli such as temperature [449], $\mathrm{pH}$ [419] or electric fields [450] to promote controlled drug release at specific locations or targets. Thermosensitive poly (N-isopropylacrylamide) brushes grafted on the surface of BNC reversibly collapsed above the lower critical solution temperature of the polymer $\left(32^{\circ} \mathrm{C}\right)$ leading to the formation of a protective, dehydrated shell which significantly reduced water exchange and enabled better reswelling after heat treatment [449]. pH sensitivity is a typical example to trigger a controlled gastrointestinal release using ionizable polymers like sodium alginate [419], poly (acrylic acid) (PAA) [440], poly(N-methacryloyl glycine) [451], gelatin [452,453], carboxymethylcellulose [454] or resilin-like polypeptides [455] grafted or blended to nanocellulose. For example BNC-g-PAA protected loaded albumin in the acidic gastric fluid $(\mathrm{pH} 1.2)$ with a cumulative release of less than $10 \%$, while after deprotonation of the carboxylic groups of PAA in intestinal fluid ( $\mathrm{pH}$ 6.8) the protein could be released up to $90 \%$ due to an enhanced swelling because of electrostatic repulsion [440]. Ionization-dependent swelling and release could also be achieved by applying an electric stimulus as shown for sodium alginate-nanocellulose composites [450]. The hybrid hydrogels showed an increasing swelling ratio from 8 to 14 times its dry weight under an increasing applied voltage up to $0.5 \mathrm{~V}$ followed by a release rate dependent on the applied electric 


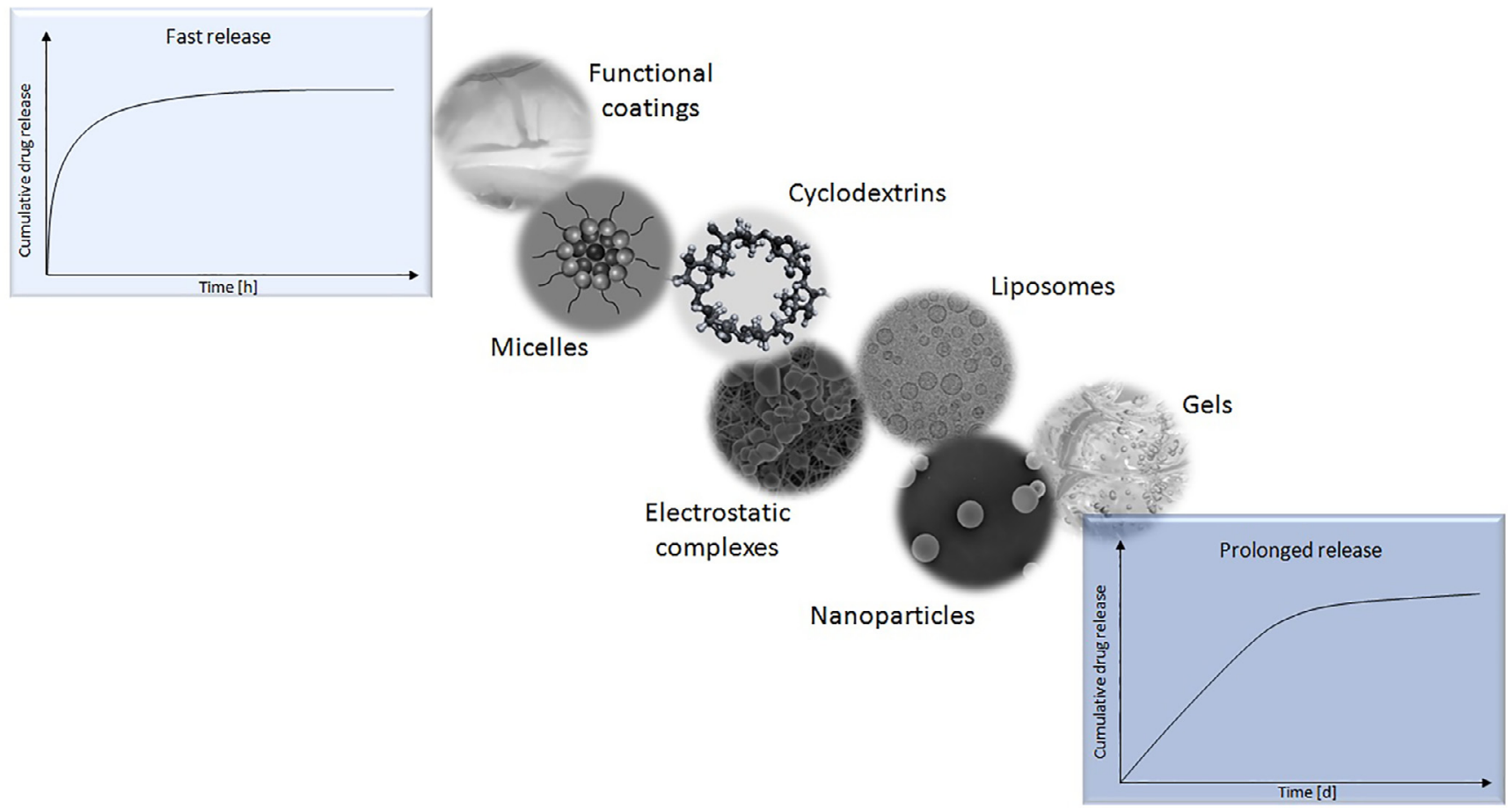

FIGURE 17

Strategies based on the combination of nanocellulose and further carriers to accomplish the controlled fast and prolonged release of drugs.

TABLE 3

\begin{tabular}{ll}
\hline Overview of drugs incorporated into BNC, CNFs, or CNCs. \\
\hline Antiseptics & $\begin{array}{l}\text { Octenidine [420], polyhexanide, povidone- } \\
\text { iodine [411] } \\
\text { Lidocaine [413], procaine [437] }\end{array}$ \\
$\begin{array}{ll}\text { Local anesthetics } & \text { Paracetamol [410], ibuprofen [435], diclofenac } \\
\text { antiphlogistics } & {[423], \text { theophylline [419], indomethacin }} \\
& {[414,415], \text { berberine [427], beclomethasone }} \\
& \text { [414,438] } \\
\text { Antibiotics } & \text { Tetracycline [434], gentamycine, ampicillin [439] } \\
\text { Antihypertensives } & \text { Propranolol [432], metoprolol, verapamil [434] } \\
\text { Cytostatics } & \text { Doxorubicine [425], paclitaxel [432] } \\
\text { Natural extract } & \text { Scrophularia striata Boiss. Extract [412] } \\
\text { Peptides or proteins } & \text { Albumin [425,430,440], laccase [441], lipase } \\
& \text { [442], lysozyme [443] }\end{array}$ \\
\hline
\end{tabular}

strength. For example, after $8 \mathrm{~h}$, the amount of drug released at $0.5 \mathrm{~V}$ was twice as high as that of $0 \mathrm{~V}$. For other cellulose-based hydrogels a similar stimuli-responsive drug release could be obtained during shrinking or swelling of the material as a function of an external stimulus such as $\mathrm{pH}$ or temperature as shown for insulin [456], oxaliplatin [457], ketoprofen, and albumin [458].

Combinations of micro- or nanoparticles [426,438,459], cyclodextrins [412,418,460], micelles or gels [37] with BNC or CNCs accomplished higher loading efficiencies, revealed additional retarding barriers and were preferentially used to prolong drug release (Fig. 17). As an example, the in situ formation of Poloxamer 407 gels $(18.5 \%)$ in the BNC network reduced the burst release and retarded the release of octenidine up to $196 \mathrm{~h}$ compared to $24 \mathrm{~h}$ of the BNC alone [37].
In conclusion, tremendous attention has been given to better understand the interactions between nanocellulose carriers and drugs and the evaluation of basic concepts in the last 10 years. Although several loading techniques were developed and different release profiles adapted, all these strategies mostly follow the same principles. For the next generation of nanocellulose carriers more sophisticated release concepts are suggested to be in the focus for immediate and sustained drug release as well as formulations for critical drugs (e.g., highly lipophilic, unstable or large sized). Furthermore, since only limited reports that overcome the barriers to practice with descriptions of applications in the body are available, the transfer from the laboratory bench to real applications seems to be the next step.

When thinking about medical and pharmaceutical applications of nanocellulose, especially $\mathrm{BNC}$, it has to be taken into consideration that cost-effective and fast production processes are required which can be afforded by the healthcare systems. As described above, several production concepts are underway with the potential to be not only effective and affordable in a few years, but also to have an advantage in competition due to the high reproducibility of the materials and homogeneity of the 3D network structures.

\section{Economics of nanocelluloses}

A variety of market reports and guides for end users have been published forecasting the nanocellulose market, including from companies such as Future Markets Inc. [276], Global Industry Analysts Inc., Allied Market Research, Vireo Advisors, RISI, Market Intel, LLC and a new book "Nanocellulose Producers, Products, and Applications: A Guide for End Users" published by TAPPI [395]. The unifying themes have been the need to look 
for high value and/or high volume applications and understand the value proposition, for example, in terms of light-weighting, low loading requirements and replacing other (undesirable) materials. As such, the cost of nanocellulose per kilogram should not be the "end all" metric in the value proposition [461].

The key measures to reduce BNC production costs are (i) the use of alternative feedstocks especially plant wastes, (ii) novel bioreactor designs and (iii) scale-up (see also Section Up-scaled production). A detailed discussion of $\mathrm{BNC}$ production costs is difficult, since this is information most producers want to protect. In addition, whether a BNC-based product is competitive strongly depends on the specific application, the production scale in relation to the market need, and the material quality (which again depends on specific bacteria strains, choice for certain feedstocks and bioreactor design). Thus, a high-price implant material, for example, a first artificial heart bypass, can be more competitive than a Nata de Coco-based food thickener obtained in mass production. There are no standard answers regarding $\mathrm{BNC}$ production costs that can be given at this point.

The economics of making CNF materials is primarily dependent on the type of fiber pre-treatment (e.g., enzymatic, carboxymethylation, TEMPO-modified CNF etc.). The cheapest process is probably the enzymatic pre-treatment process, where the cost for making CNF from the pulp integrated in a pulp mill is $0.4 € / \mathrm{kg}$, which today is in operation in large-scale papermaking applications. For non-integrated use of CNF in papermaking applications, the cost including pulp cost and profits should be lower than $2.5 € / \mathrm{kg}$ [462]. Additionally, the cost for CNCproduction may be taken as a guideline to estimate the cost for the manufacture of carboxymethylated CNF. For TEMPOmodified CNF, the recycling of the TEMPO catalyst is necessary in order to decrease the cost, but this is still proprietary technology.

Similar to BNC and CNF, the cost of production of CNCs depends on the isolation route and attainable yields - currently the largest scale production (and most uniform and reproducible commercially available CNCs [279]) uses the sulfuric acid hydrolysis process. Sulfuric acid is low cost (and can be recycled), CNC yields are high and degraded sugars can be fermented to biofuels for additional cost benefit; however, separation, heating and drying processes have high energy demands and associated costs. Additionally, there are new CNC production methods on the horizon that may be cheaper. These include oxidation methods, subcritical water processing/hot-water pre-extraction and more mild reaction conditions whereby CNCs are produced as one output of the biorefinery process. While sale prices are expected to drop below $15 € / \mathrm{kg}$ for sulfuric acid hydrolyzed CNCs (and potentially cheaper for other processes), R\&D samples are currently sold at approximately $800 € / \mathrm{kg}$. For CNCs, the starting cellulose material quality does not greatly affect the final nanoparticle performance and as such, using waste streams and undesirable biomass feeds may help to lower production costs. Another option that may be more economically viable is the concurrent production of CNF and CNCs (and sugars) using less harsh reaction conditions, such as demonstrated recently using dicarboxylic acid hydrolysis [463].

\section{Conclusions}

The goal of the present review is to emphasize that nanocelluloses are a prime example of natural sources for groundbreaking applications in materials science and technology. As such, the focus is directed toward $\mathrm{BNC}, \mathrm{CNF}$, and $\mathrm{CNC}$ research and development which has occurred primarily over the last five years. Application possibilities are numerous and diverse - from massproduced industrial products to high-end medical products. In some fields, all three types of nanocellulose can be used, while for other applications the type is more crucial. For example, BNC is particularly suited for use as scaffolds for cell cultivation and drug delivery as well as medical implants. Currently some BNC-based medical products - e.g., SYNTHECEL ${ }^{\circledR}$ Dura Repair (implant) produced by DePuy Synthes, USA, epicite ${ }^{\text {hydro }}$ (wound dressing) produced by JeNaCell $\mathrm{GmbH}$, Germany, or Celmat (wound dressing), produced by BOWIL, Poland - are on the market. These products are FDA approved and/or CE-certified.

In the case of CNF the main large-scale applications include papermaking strength additives and composite applications but also in the fields of rheological modifiers (e.g., food and paint applications) and the emerging fields of electronic and cosmetic applications and nanofilter devices. CNCs are most destined as interface stabilizers, rheological modifiers, as films/coatings and reinforcing agents in polymer composites but also are nontoxic and show great potential in biomedical devices as well.

Around the globe, research groups and, increasingly, companies are extensively working to expand the market for nanocellulose products and to open up totally new application areas. Key aspects for future development include the design of nanocelluloses for specific user requirements, the reduction of production costs, and the customization/functionalization using post production steps and different types of compounding/processing.

\section{Acknowledgments}

Dana Kralisch and Dagmar Fischer gratefully acknowledge the Free State of Thuringia and the European Social Fund (2016 FGR 0045) for funding. Dagmar Fischer would like to thank Yvette Pötzinger and Berit Karl for the excellent editorial support. Dieter Klemm, Friederike Kramer and Katrin Petzold-Welcke are grateful for the support by the Federal Ministry of Economic Affairs and Energy, ZIM (KF2748903MF4 and KF2386003MF3). Thanks are due to the employees of Jenpolymer Materials Ltd. \& Co. KG and the Polymet Jena Association, especially Priv.-Doz. Dr. Wolfgang Fried, and Prof. Dr. Raimund W. Kinne, Experimental Rheumatology Unit, Department of Orthopedics, Jena University Hospital, Germany as well as to Dr. Detlef Gorski and Elke Langhammer, SuraChemicals GmbH, Jena, Germany for effective and helpful cooperation and stimulating interaction. Dieter Klemm and Friederike Kramer would like to thank Katharina Horn for the excellent editorial support.

Miguel Gama acknowledges the funding from QREN ("Quadro de Referência Estratégica Nacional") through the BioTecNorte operation (NORTE-01-0145-FEDER-000004) funded by the European Regional Development Fund under the scope of Norte2020-Programa Operacional Regional do Norte. 
Tom Lindström acknowledges RISE Bioeconomy for support and permission to publish. Emily Cranston and Stephanie Kedzior are thankful for funding from the Natural Sciences and Engineering Research Council of Canada (NSERC) in the form of a Discovery Grant (RGPIN 402329) and PGSD graduate student scholarship, as well as support from the Faculty of Engineering at McMaster University.

No writing assistance was utilized in the production of this manuscript.

\section{Declaration of interest}

Dana Kralisch is CTO of JeNaCell GmbH. The author has no other relevant affiliations or financial involvement with any organization or entity with a financial interest in or financial conflict with the subject matter or materials discussed in the manuscript apart from those disclosed. Dagmar Fischer is a member of the scientific board of JeNaCell GmbH.

\section{References}

[1] R. Kumar, R.K. Sharma, A.P. Singh, Polym. Bull. (2017) 1-30, https://doi.org/ 10.1007/s00289-017-2136-6.

[2] T. Van de Ven, L. Godbout, InTech (2013).

[3] J.-L. Wertz, O. Bédué, J.-P. Mercier, Cellulose Science and Technology, EPFL Press, Lausanne, 2010.

[4] H. Sixta, Handbook of Pulp, Wiley-VCH Verlag GmbH, Weinheim, Germany, 2006. doi:10.1002/9783527619887.

[5] D. Klemm et al., Angew. Chem. Int. Ed. 44 (2005) 3358-3393, https://doi.org/ 10.1002/anie.200460587.

[6] D. Klemm, B. Philipp, T. Heinze, U. Heinze, W. Wagenknecht, Comprehensive Cellulose Chemistry, Wiley-VCH Verlag GmbH \& Co. KGaA, Weinheim, FRG, 1998. doi: 10.1002/3527601929.

[7] N.L. V Carreño, A.M. Barbosa, B.S. Noremberg, M.M.S. Salas, S.C.M. Fernandes, J. Labidi, Advances in Nanostructured Cellulose-based Biomaterials, Springer International Publishing, Cham, 2017. doi:10.1007/978-3-319-58158-3.

[8] M. Jorfi, E.J. Foster, J. Appl. Polym. Sci. 132 (2015) 41719, https://doi.org/ 10.1002/app.41719.

[9] N. Lin, A. Dufresne, Eur. Polym. J. 59 (2014) 302-325, https://doi.org/10.1016/ j.eurpolymj.2014.07.025.

[10] D. Klemm et al., Angew. Chem. Int. Ed. 50 (2011) 5438-5466, https://doi.org/ 10.1002/anie.201001273.

[11] Y. Habibi, L.A. Lucia, O.J. Rojas, Chem. Rev. 110 (2010) 3479-3500.

[12] J.F. Vincent, Mater. Today. 5 (2002) 28-41, https://doi.org/10.1016/S13697021(02)01237-3.

[13] C. Somerville, Annu. Rev. Cell Dev. Biol. 22 (2006) 53-78, https://doi.org/ 10.1146/annurev.cellbio.22.022206.160206.

[14] R.M. Brown, J. Polym. Sci. Part A Polym. Chem. 42 (2004) 487-495, https://doi. org/10.1002/pola.10877.

[15] T. Heinze, Cellulose: Structure and Properties, in: O.J. Rojas (ed.), Cellul. Chem. Prop. Fibers, Nanocelluloses Adv. Mater. Adv. Polym. Sci. Vol 271, Springer, Cham, 2015. doi: 10.1007/12_2015_319.

[16] A.D. French, M. Santiago, Cellulose 20 (2013) 583-588, https://doi.org/ 10.1007/s10570-012-9833-y.

[17] P. Ahvenainen, I. Kontro, K. Svedström, Cellulose 23 (2016) 1073-1086. doi: 10.1007/s10570-016-0881-6.

[18] U.P. Agarwal et al., Cellulose 24 (2017) 1971-1984. doi: 10.1007/s10570-0171259-0.

[19] S. Park, J.O. Baker, M.E. Himmel, Biotechnol. Biofuels 3 (2010) 10, https://doi. org/10.1186/1754-6834-3-10.

[20] S.P. Rowland, E.J. Roberts, Polym. Chem. 10 (1972) 2447-2461, https://doi. org/10.1002/pol.1972.150100819.

[21] I. Usov et al., Nat. Commun. 6 (2015) 7564.

[22] P.T. Larsson, K. Wickholm, T. Iversen, Carbohydr. Polym. 302 (1997) 19-25 doi: 10.1016/S0008-6215(97)00130-4

[23] U.P. Agarwal et al., Cellulose 23 (2016) 125-144.

[24] X. Xu et al., ACS Appl. Mater. Interfaces 5 (2013) 2999-3009, https://doi.org/ $10.1021 / \mathrm{am} 302624 \mathrm{t}$

[25] L. Chen et al., Cellulose 22 (2015) 1753-1762.
[26] I.M. Saxena, T. Dandekar, R.M. Brown, Mechanisms in cellulose biosynthesis, Esf.edu. (n.d.).

[27] Canadian Standards Association, Cellulosic nanomaterials - Test methods for characterization (CSA Z5100-14), 2014.

[28] C.L. Rosen et al., Neurosurgery 69 (2011) 1093-1103, https://doi.org/10.1227/ NEU.0b013e3182284aca.

[29] A. Müller et al., RSC Adv. 4 (2014) 57173-57184, https://doi.org/10.1039/ C4RA09898F.

[30] M. Phisalaphong, N. Chiaoprakobkij, Applications and Products-Nata de Coco, in: M. Gama, P. Gatenholm, D. Klemm (Eds.), Bact. Nanocellulose a Sophistic. Multifunct. Mater., CRC Press, 2013, pp. 143-156.

[31] National Research Council (U.S.). Panel on the Applications of Biotechnology to Traditional Fermented Foods., Applications of Biotechnology to Traditional Fermented Foods: Report of an ad hoc panel of the Board on Science and Technology for International Development, National Academy Press, 1992.

[32] M.M. Lapuz, E.G. Gallardo, M. Palo, Philipp. J. Sci. 96 (1967) 91-109.

[33] S. Il Jeong et al., Mol. Cell. Toxicol. 6 (2010) 370-377, https://doi.org/10.1007/ s13273-010-0049-7.

[34] G. Helenius et al., J. Biomed. Mater. Res. Part A 76A (2006) 431-438, https:// doi.org/10.1002/jbm.a.30570.

[35] D.A. Schumann et al., Cellulose 16 (2009) 877-885, https://doi.org/10.1007/ s10570-008-9264-y.

[36] I.F. Almeida et al., Eur. J. Pharm. Biopharm. 86 (2014) 332-336, https://doi.org/ 10.1016/j.ejpb.2013.08.008.

[37] Y. Alkhatib et al., Eur. J. Pharm. Biopharm. 112 (2017) 164-176.

[38] H.G. de Oliveira Barud, R.R. da Silva, Carbohydr. Polym. 153 (2016) 406-420, https://doi.org/10.1016/j.carbpol.2016.07.059.

[39] A.M.A. Gallegos et al., BioResources 11 (2016) 5641-5655, https://doi.org/ 10.15376/biores.11.2.Gallegos.

[40] A.F. Jozala et al., Appl. Microbiol. Biotechnol. 100 (2016) 2063-2072, https:// doi.org/10.1007/s00253-015-7243-4.

[41] P. Gatenholm, D. Klemm, MRS Bull. 35 (2010) 208-213, https://doi.org/ $10.1557 / \mathrm{mrs} 2010.653$.

[42] M. Gama, P. Gatenholm, D. (Dieter) Klemm, Bacterial nanocellulose: a sophisticated multifunctional material, CRC Press, Boca Raton, 2013.

[43] M. Gama, F. Dourado, S. Bielecki, Bacterial Nanocellulose: From Biotechnology to Bio-economy, Elsevier, Amsterdam, 2016.

[44] M.I.H. Mondal, Structure of Nascent Microbial Cellulose and Characterization Microbial Cellulose Synthesis, LAP LAMBERT Academic Publishing, Saarbrücken, 2012.

[45] S. Keshk, Scope on Bacterial Cellulose Production, LAP LAMBERT Academic Publishing, Saarbrücken, 2011.

[46] M.E.S. Piadozo, Nata de Coco industry in the Philippines, in: M. Gama, F. Dourado, S. Bielecki (Eds.), Bact. Nanocellulose from Biotechnol. to BioEconomy, Elsevier, Amsterdam, 2016, pp. 231-236.

[47] M. Phisalaphong, T.-K. Tran, S. Taokaew, R. Budiraharjo, G.G. Febriana, D.-N. Nguyen, S. Chu-Ky, F. Dourado, Nata de coco Industry in Vietnam, Thailand, and Indonesia, in: M. Gama, F. Dourado, S. Bielecki (eds.), Bact. Nanocellulose from Biotechnol. to Bio-Economy, Elsevier, Amsterdam, 2016: pp. 231-236. doi:10.1016/B978-0-444-63458-0.00014-7.

[48] K.-Y. Lee et al., Macromol. Biosci. 14 (2014) 10-32, https://doi.org/10.1002/ mabi.201300298.

[49] Y. Pötzinger, D. Kralisch, D. Fischer, Ther. Deliv. 8 (2017) 753-761, https://doi. org/10.4155/tde-2017-0059.

[50] D. Kralisch, N. Hessler, Large-scale production of BNC: state and challenges, in: M. Gama, P. Gatenholm, D. Klemm (Eds.), Bact. Nanocellulose a Sophistic. Multifunct. Mater, CRC Press, Boca Raton, 2013, pp. 43-72.

[51] Y.-J. Kim et al., Appl. Biochem. Biotechnol. 137-140 (2007) 529-537, https:// doi.org/10.1007/s12010-007-9077-8.

[52] D. Klemm et al., Prog. Polym. Sci. 26 (2001) 1561-1603, https://doi.org/ 10.1016/S0079-6700(01)00021-1.

[53] A. Bodin et al., Biotechnol. Bioeng. 97 (2007) 425-434, https://doi.org/ $10.1002 /$ bit. 21314

[54] M.L. Cacicedo et al., Bioresour. Technol. 213 (2016) 172-180, https://doi.org/ 10.1016/j.biortech.2016.02.071.

[55] S. Premjet, D. Premjet, Y. Ohtani, FIBER 63 (2007) 193-199, https://doi.org/ 10.2115/fiber.63.193.

[56] F. Hong, K. Qiu, Carbohydr. Polym. 72 (2008) 545-549, https://doi.org/ 10.1016/i.carbpol.2007.09.015.

[57] R.M. Brown et al., Am. J. Bot. 79 (1992) 1247-1258, https://doi.org/10.2307/ 2445052 .

[58] M. Onodera et al., Biotechnol. Bioprocess Eng. 7 (2002) 289-294, https://doi. org/10.1007/BF02932838. 
[59] A. Putra et al., Cell. Commun. 15 (2008) 73-78.

[60] K.-C. Cheng, J.M. Catchmark, A. Demirci, J. Biol. Eng. 3 (2009) 12, https://doi. org/10.1186/1754-1611-3-12.

[61] S.-C. Wu, M.-H. Li, J. Biosci. Bioeng. 120 (2015) 444-449, https://doi.org/ 10.1016/j.jbiosc.2015.02.018.

[62] A. Sani, Y. Dahman, J. Chem. Technol. Biotechnol. 85 (2009) 151-164, https:// doi.org/10.1002/jctb.2300.

[63] C.N. Choi et al., Korean J. Chem. Eng. 26 (2009) 136-140, https://doi.org/ 10.1007/s11814-009-0021-1.

[64] D. Kralisch et al., Biotechnol. Bioeng. 105 (2009) 740-747, https://doi.org/ 10.1002/bit.22579.

[65] S. Pelzer, Biol. Unserer Zeit. 42 (2012) 98-106, https://doi.org/10.1002/ biuz. 201210472

[66] U. Römling, M.Y. Galperin, Trends Microbiol. 23 (2015) 545-557, https://doi org/10.1016/j.tim.2015.05.005.

[67] D.O. Klemm, et al., Why nanocelluloses as medical implants? An innovative approach for an unsolved problem, Abstr. Pap. 245th ACS Natl. Meet. Expo. New Orleans, LA, United States, 2013.

[68] D. Klemm, et al., Vorrichtung zur Herstellung von Hohlkörpern aus mikrobiellem Polymer, DE 102012201272 A1, 2012.

[69] W. Fried, et al., Verfahren zur Herstellung von Hohlkörpern aus mikrobieller Cellulose, DE 102012201268 A1, 2012.

[70] P. Echlin, Handbook of Sample Preparation for Scanning Electron Microscopy and X-ray Microanalysis, Springer, 2009.

[71] T. Kondo, et al., Wet pulverizing of polysaccharides, US 7357339 B2, 2008.

[72] T. Kondo et al., Carbohydr. Polym. 112 (2014) 284-290, https://doi.org/ 10.1016/j.carbpol.2014.05.064.

[73] R. Kose et al., Biomacromolecules 12 (2011) 716-720, https://doi.org/10.1021/ bm1013469.

[74] K. Tsuboi, S. Yokota, T. Kondo, Nord. Pulp Pap. Res. J. 29 (2014) 069-076, https://doi.org/10.3183/NPPRJ-2014-29-01-p069-076.

[75] Y. Kawano, T. Kondo, Chem. Lett. 43 (2014) 483-485.

[76] T. Kondo et al., Mater. Res. Express. 1 (2014) 45016, https://doi.org/10.1088/ 2053-1591/1/4/045016.

[77] R. Kose, T. Kondo, Sen'i Gakkaishi. 67 (2011) 91-95.

[78] R. Kose, W. Kasai, T. Kondo, Sen'i Gakkaishi. 67 (2011) 163-168.

[79] R. Kose, T. Kondo, J. Appl. Polym. Sci. 128 (2013) 1200-1205, https://doi.org/ 10.1002/app.38308.

[80] S. Brunauer, P.H. Emmett, E. Teller, J. Am. Chem. Soc. 60 (1938) 309-319, https://doi.org/10.1021/ja01269a023.

[81] R.H. Atalla, D.L. Vanderhart, Science (80-.). 223 (1984) 283-285.

[82] H. Yamamoto, F. Horii, A. Hirai, Cellulose 3 (1996) 229-242, https://doi.org/ $10.1007 / \mathrm{BFO} 2228804$.

[83] J. Sugiyama, J. Persson, H. Chanzy, Macromolecules 24 (1991) 2461-2466, https://doi.org/10.1021/ma00009a050.

[84] Y. Kataoka, T. Kondo, Macromolecules 29 (1996) 6356-6358.

[85] H. Yamamoto, F. Horii, Macromolecules 26 (1993) 1313-1317, https://doi.org/ 10.1021/ma00058a020.

[86] N. Hayashi, T. Kondo, M. Ishihara, Carbohydr. Polym. 61 (2005) 191-197, https://doi.org/10.1016/j.carbpol.2005.04.018.

[87] P. Chu, Mater. Sci. Eng. R Reports. 36 (2002) 143-206, https://doi.org/10.1016/ S0927-796X(02)00004-9.

[88] Z. Ma, Z. Mao, C. Gao, Colloid. Surfaces B Biointerfaces 60 (2007) 137-157, https://doi.org/10.1016/j.colsurfb.2007.06.019.

[89] Y.-X. Wang et al., Pharm. Res. 21 (2004) 1362-1373, https://doi.org/10.1023/B PHAM.0000036909.41843.18.

[90] A. Vesel et al., Surf. Interface Anal. 40 (2008) 1444-1453, https://doi.org/ 10.1002/sia.2923.

[91] C. Lucchesi et al., J. Mater. Sci. Mater. Med. 19 (2008) 635-643, https://doi.org/ 10.1007/s10856-007-0169-3.

[92] U. Hersel, C. Dahmen, H. Kessler, Biomaterials 24 (2003) 4385-4415, https:// doi.org/10.1016/S0142-9612(03)00343-0.

[93] A. Bodin et al., Biomacromolecules 8 (2007) 3697-3704, https://doi.org/ 10.1021/bm070343q.

[94] H. Fink et al., J. Tissue Eng. Regen. Med. 5 (2011) 454-463, https://doi.org/ 10.1002/term.334.

[95] F.K. Andrade et al., Acta Biomater. 6 (2010) 4034-4041, https://doi.org/ 10.1016/j.actbio.2010.04.023.

[96] F.K. Andrade et al., J. Biomed. Mater. Res. Part A. 98A (2011) 554-566, https:// doi.org/10.1002/jbm.a.33148.

[97] Y. Wan et al., Polym. Adv. Technol. 22 (2011) 2643-2648, https://doi.org/ $10.1002 /$ pat.1692.

[98] K. Watanabe et al., Cytotechnology 13 (1993) 107-114.
[99] D.W. Hutmacher, Biomaterials 21 (2000) 2529-2543, https://doi.org/10.1016/ S0142-9612(00)00121-6.

[100] A. Svensson et al., Biomaterials 26 (2005) 419-431, https://doi.org/10.1016/j. biomaterials.2004.02.049.

[101] R.A.N. Pertile et al., Carbohydr. Polym. 82 (2010) 692-698, https://doi.org/ 10.1016/j.carbpol.2010.05.037.

[102] W. Bhanthumnavin et al., Surf. Coat. Technol. 306 (2016) 272-278, https:// doi.org/10.1016/j.surfcoat.2016.06.035.

[103] J. Li et al., Mater. Sci. Eng. C 29 (2009) 1635-1642, https://doi.org/10.1016/j. msec.2009.01.006.

[104] S.A. Hutchens et al., Cellulose 16 (2009) 887-898, https://doi.org/10.1007/ s10570-009-9300-6.

[105] H. Shim et al., Polym. Plast. Technol. Eng. 54 (2015) 305-309, https://doi.org/ 10.1080/03602559.2014.977428

[106] S. Bottan et al., ACS Nano 9 (2015) 206-219, https://doi.org/10.1021/ nn5036125.

[107] A. Bodin et al., Biomaterials 31 (2010) 8889-8901, https://doi.org/10.1016/j. biomaterials.2010.07.108.

[108] X. Lv et al., ACS Biomater. Sci. Eng. 2 (2016) 19-29, https://doi.org/10.1021/ acsbiomaterials. 5 b00259.

[109] J.-W. Huang et al., Biomed. Mater. 10 (2015) 55005, https://doi.org/10.1088/ 1748-6041/10/5/055005.

[110] J. Wippermann et al., Eur. J. Vasc. Endovasc. Surg. 37 (2009) 592-596, https:// doi.org/10.1016/j.ejvs.2009.01.007.

[111] M. Scherner et al., J. Surg. Res. 189 (2014) 340-347, https://doi.org/10.1016/j. jss.2014.02.011.

[112] C.J. Malm et al., Scand. Cardiovasc. J. 46 (2012) 57-62, https://doi.org/ 10.3109/14017431.2011.623788.

[113] A.F. Leitão et al., Macromol. Biosci. 16 (2016) 139-150, https://doi.org/ 10.1002/mabi.201500251.

[114] Y. Li et al., Adv. Healthc. Mater. 6 (2017) 1601343, https://doi.org/10.1002/ adhm.201601343.

[115] C. Xu et al., Int. J. Mol. Sci. 15 (2014) 10855-10867, https://doi.org/10.3390/ ijms150610855.

[116] F. de M.T. de Lima, et al., J. Mater. Sci. Mater. Med. 28 (2017) 37. doi:10.1007/ s10856-016-5828-9.

[117] F.C.A. Silveira, F.C.M. Pinto, Braz. J. Otorhinolaryngol. 82 (2016) 203-208, https://doi.org/10.1016/j.bjorl.2015.03.015.

[118] J. Kim et al., Adv. Healthc. Mater. 2 (2013) 1525-1531, https://doi.org/ $10.1002 / \mathrm{adhm} .201200368$.

[119] S. Biskin et al., Eur. Arch. Oto-Rhino-Laryngol 273 (2016) 3561-3565, https:// doi.org/10.1007/s00405-016-3959-8.

[120] L.M. Cavalcanti et al., Rev. Col. Bras. Cir. 44 (2017) 72-80, https://doi.org/ 10.1590/0100-69912017001011.

[121] J. Ran et al., Mater. Sci. Eng. C 78 (2017) 130-140, https://doi.org/10.1016/j. msec.2017.04.062.

[122] J.M. Gutiérrez-Hernández et al., Mater. Sci. Eng. C 75 (2017) 445-453, https:// doi.org/10.1016/j.msec.2017.02.074.

[123] Y. Huang et al., Mater. Sci. Eng. C 75 (2017) 1034-1041, https://doi.org/ 10.1016/j.msec.2017.02.174.

[124] H. Martínez àvila et al., Biomaterials 44 (2015) 122-133, https://doi.org/ 10.1016/j.biomaterials.2014.12.025.

[125] F.C. de Souza et al., J. Voice 25 (2011) 765-769, https://doi.org/10.1016/j. jvoice.2010.07.005.

[126] C. Zhu et al., Turk. J. Med. Sci. 45 (2015) 762-770.

[127] N. Lang et al., Eur. J. Cardio-Thoracic Surg. 47 (2015) 1013-1021, https://doi. org/10.1093/ejcts/ezu292.

[128] T. Khan, J.K. Park, J.-H. Kwon, Korean J. Chem. Eng. 24 (2007) 816-826, https://doi.org/10.1007/s11814-007-0047-1.

[129] A. Okiyama, M. Motoki, S. Yamanaka, Food Hydrocoll. 6 (1993) 493-501, https://doi.org/10.1016/S0268-005X(09)80073-8.

[130] A. Okiyama, M. Motoki, S. Yamanaka, Food Hydrocoll. 6 (1993) 503-511, https://doi.org/10.1016/S0268-005X(09)80074-X.

[131] A. Okiyama, M. Motoki, S. Yamanaka, Processing of the gelatinous cellulose for food materials, Food Hydrocoll. 6 (1992) 479-487, https://doi.org/10.1016/ S0268-005X(09)80033-7.

[132] R. Clark, et al., Food products containing bacterial cellulose, EP0934070 A1, 1997.

[133] R.S. Stephens, J.A. Westland, A.N. Neogi, Method of using bacterial cellulose as a dietary fiber component, US4960763 A, 1988.

[134] K. Watanabe, et al., Low calorie foodstuff, aqueous paste composition, as well as production process thereof, US5690981 A, 1995.

[135] Z.F. Yang, et al., Bacterial cellulose-containing formulations, US8053216 B2, 2011. 
[136] F. Hong, G. Yang, High-Dietary-Fiber Biscuit Containing Bacterial Cellulose and Preparation Method Thereof, CN101919431 A, 2013.

[137] M. Echeverry-Rendon et al., Macromol. Biosci. 17 (2017) 1600382, https://doi. org/10.1002/mabi.201600382.

[138] C. Busuioc et al., Ceram. Int. 42 (2016) 15449-15458, https://doi.org/10.1016/ j.ceramint.2016.06.196.

[139] J.H. Kim et al., Carbohydr. Polym. 157 (2017) 137-145, https://doi.org/ 10.1016/j.carbpol.2016.09.074.

[140] P. Zhang et al., Biotechnol. Prog. 32 (2016) 1077-1084, https://doi.org/ 10.1002/btpr.2280.

[141] F. Hong, B. Wei, L. Chen, Biomed Res. Int. 2015 (2015) 560365. doi:10.1155/ $2015 / 560365$.

[142] J. Tang et al., J. Chem. Technol. Biotechnol. 92 (2017) 1218-1228, https://doi. org/10.1002/jctb.5111.

[143] P. Jiang et al., J. Biomater. Sci. Polym. Ed. 29 (2018) 107-124, https://doi.org/ 10.1080/09205063.2017.1403149.

[144] J. Chen et al., J. Mater. Chem. B 5 (2017) 3640-3650, https://doi.org/10.1039/ C7TB00485K.

[145] H. Ahrem et al., Acta Biomater. 10 (2014) 1341-1353, https://doi.org/10.1016/ j.actbio.2013.12.004.

[146] P. Krontiras, P. Gatenholm, D.A. Hägg, J. Biomed. Mater. Res. B. Appl. Biomater. 103 (2015) 195-203, https://doi.org/10.1002/jbm.b.33198.

[147] M. Park et al., Carbohydr. Polym. 158 (2017) 133-140, https://doi.org/ 10.1016/J.CARBPOL.2016.12.007.

[148] A.C. Khorasani, S.A. Shojaosadati, Food Hydrocoll. 63 (2017) 273-285, https:// doi.org/10.1016/J.FOODHYD.2016.09.002.

[149] I. Chiulan et al., J. Appl. Polym. Sci. 135 (2018) 45800, https://doi.org/ 10.1002/app.45800.

[150] L. Urbina et al., J. Appl. Polym. Sci. 133 (2016), https://doi.org/10.1002/ app. 43669 .

[151] H. Uyama, Composite sheet containing bacterial cellulose and hydrophilic polymer for water absorption, JP 2017155171A, 2017.

[152] R. Liu et al., Chem. A Eur. J. 23 (2017) 2610-2618, https://doi.org/10.1002/ chem.201604535.

[153] F. Wang et al., Compos. Sci. Technol. 128 (2016) 33-40, https://doi.org/ 10.1016/J.COMPSCITECH.2016.03.012.

[154] Q. Zheng, et al., Preparation method for cellulose-based aluminum-doped zinc oxide transparent conductive material, CN106373669 A, 2017.

[155] F. Quero et al., Biomacromolecules 16 (2015) 1784-1793, https://doi.org/ 10.1021/acs.biomac.5b00345.

[156] A.N. Aleshin et al., Synth. Met. 199 (2015) 147-151, https://doi.org/10.1016/J SYNTHMET.2014.11.022.

[157] S. Ifuku et al., Biomacromolecules 8 (2007) 1973-1978, https://doi.org/ 10.1021/BM070113B.

[158] M. Nogi et al., Appl. Phys. Lett. 89 (2006) 233123, https://doi.org/10.1063/ 1.2403901.

[159] A.N. Nakagaito, H. Yano, Am. Chem. Soc., 2006, 151-168. doi:10.1021/bk2006-0938.ch011.

[160] H. Yano et al., Adv. Mater. 17 (2005) 153-155, https://doi.org/10.1002/ adma.200400597.

[161] C.M. Vu et al., Polym. Test. 61 (2017) 150-161, https://doi.org/10.1016/J. POLYMERTESTING.2017.05.013.

[162] L. Yue et al., Compos. Sci. Technol. 145 (2017) 122-131, https://doi.org/ 10.1016/J.COMPSCITECH.2017.04.002.

[163] L. Yue et al., RSC Adv. 6 (2016) 68599-68605, https://doi.org/10.1039/ C6RA07646G.

[164] H. Do Phan, et al., Tap Chi Hoa Hoc. 53 (2015) 336-340.

[165] B. Wang et al., RSC Adv. 7 (2017) 42113-42122, https://doi.org/10.1039/ C7RA07731A.

[166] B. Wang et al., Polymers (Basel) 8 (2016) 129, https://doi.org/10.3390/ polym8040129.

[167] Y. Numata et al., Carbohydr. Polym. 173 (2017) 67-76, https://doi.org/ 10.1016/j.carbpol.2017.05.077.

[168] A. Kalytta-Mewes et al., J. Mater. Chem. A 3 (2015) 20829-21360.

[169] S. Dutta et al., Mater. Horizons 4 (2017) 522-545, https://doi.org/10.1039/ C6MH00500D

[170] S.H. Yoon et al., Biomacromolecules 7 (2006) 1280-1284, https://doi.org/ 10.1021/bm050597g.

[171] H. Luo et al., Chem. Eng. J. 334 (2018) 1148-1158, https://doi.org/10.1016/J. CEJ.2017.11.065.

[172] R. Shao, et al., Preparation method of bacterial cellulose based composite for flocculation and decolorization of dyeing wastewater, CN 107164425, 2017. doi: $10.5772 / 52817$
[173] M. Lu et al., Gongneng Cailiao/J. Funct. Mater. 45 (2014) 23054-23058, https://doi.org/10.3969/j.issn.1001-9731.2014.23.011.

[174] N. Qiao et al., Fresenius Environ. Bull. 21 (2012) 1583-1588.

[175] D. Yu et al., Fresenius Environ. Bull. 20 (2011) 398-404.

[176] I. Siró, D. Plackett, Cellulose 17 (2010) 459-494, https://doi.org/10.1007/ s10570-010-9405-y.

[177] A. Isogai, T. Saito, H. Fukuzumi, Nanoscale 3 (2011) 71-85, https://doi.org/ 10.1039/c0nr00583e.

[178] R.J. Moon et al., Chem. Soc. Rev. 40 (2011) 3941-3994.

[179] F.W. Herrick, et al., J. Appl. Polym. Sci. Appl. Polym. Symp. (United States). 37 (1983) 797-813.

[180] A.F. Turbak, F.W. Snyder, K.R. Sandberg, J. Appl. Polym. Sci. Appl. Polym. Symp. (United States). 37 (1983) 815-827. https://www.osti.gov/scitech/ biblio/5062478 (accessed August 14, 2017).

[181] G. Siqueira, J. Bras, A. Dufresne, Polymers (Basel) 2 (2010) 728-765, https://doi. org/10.3390/polym2040728.

[182] S. Rebouillat, F. Pla, J. Biomater. Nanobiotechnol. 4 (2013) 165-188, https:// doi.org/10.4236/jbnb.2013.42022.

[183] H.P.S. Abdul Khalil et al., Carbohydr. Polym. 99 (2014) 649-665, https://doi. org/10.1016/j.carbpol.2013.08.069.

[184] M. Jonoobi et al., Cellulose 22 (2015) 935-969, https://doi.org/10.1007/ s10570-015-0551-0.

[185] J.-H. Kim et al., Int. J. Precis. Eng. Manuf. Technol. 2 (2015) 197-213, https:// doi.org/10.1007/s40684-015-0024-9.

[186] O. Nechyporchuk, M.N. Belgacem, J. Bras, Ind. Crops Prod. 93 (2016) 2-25, https://doi.org/10.1016/j.indcrop.2016.02.016.

[187] M. Hietala et al., J. Appl. Polym. Sci. 131 (2014), https://doi.org/10.1002/ app.39981.

[188] K. Suzuki et al., Cellulose 20 (2013) 201-210, https://doi.org/10.1007/s10570012-9843-9.

[189] T.T.T. Ho et al., Cellulose 22 (2015) 421-433, https://doi.org/10.1007/s10570014-0518-6.

[190] R. Baati, A. Magnin, S. Boufi, ACS Sustain. Chem. Eng. 5 (2017) 2350-2359, https://doi.org/10.1021/acssuschemeng.6b02673.

[191] X. Hua, M. Laleg, T. Owston, Cellulose nanofilaments and method to produce same, WO 2011140643 A1, 2011.

[192] J. Hiltunen, Process for producing fibrillated cellulose material, WO 2015/ 092146 A1, 2014.

[193] I. Kajanto, M. Nuopponen, J. Pere, T. Jokila, A method for producing fibrillated cellulose, WO 2015150620 A1, 2015.

[194] H. Liimatainen et al., Cellulose 22 (2015) 3151-3160, https://doi.org/10.1007/ s10570-015-0700-5.

[195] A.M. Scallan, TAPPI J. 66 (1983) 73-75.

[196] T. Lindström, Nord. Pulp Pap. Res. J. 7 (1992) 181-192, https://doi.org/ 10.3183/NPPRJ-1992-07-04-p181-192.

[197] M. Henriksson et al., Eur. Polym. J. 43 (2007) 3434-3441, https://doi.org/ 10.1016/j.eurpolymj.2007.05.038.

[198] M. Pääkkö et al., Biomacromolecules 8 (2007) 1934-1941, https://doi.org/ 10.1021/BM061215P

[199] T. Saito et al., Biomacromolecules 8 (2007) 2485-2491, https://doi.org/ 10.1021/BM0703970.

[200] L. Wågberg et al., Colloids Surf. 27 (1987) 163-173, https://doi.org/10.1016/ 0166-6622(87)80140-3.

[201] M. Ghanadpour et al., Biomacromolecules 16 (2015) 3399-3410, https://doi org/10.1021/acs.biomac.5b01117.

[202] H. Liimatainen et al., Cellulose 20 (2013) 741-749, https://doi.org/10.1007/ s10570-013-9865-y.

[203] H. Liimatainen et al., Biomacromolecules 13 (2012) 1592-1597, https://doi org/10.1021/bm300319m.

[204] A. Tejado et al., Cellulose 19 (2012) 831-842, https://doi.org/10.1007/s10570012-9694-4.

[205] A. Olszewska et al., Cellulose 18 (2011) 1213-1226, https://doi.org/10.1007/ s10570-011-9577-0.

[206] A. Naderi et al., Nord. Pulp Pap. Res. J. 31 (2016) 364-371, https://doi.org/ 10.3183/NPPRJ-2016-31-03-p364-371.

[207] T. Lindström, Curr. Opin. Colloid Interface Sci. 29 (2017) 68-75, https://doi. org/10.1016/j.cocis.2017.02.005.

[208] R.J. Kerekes, C.J. Schell, J. Pulp Pap. Sci. 18 (1992) J32-J38. http://www.refdoc fr/Detailnotice?idarticle (accessed August 14, 2017).

[209] S. Zauscher, D.J. Klingenberg, Colloids Surfaces A Physicochem. Eng. Asp. 178 (2001) 213-229, https://doi.org/10.1016/S0927-7757(00)00704-4.

[210] A.E. Horvath, T. Lindström, J. Colloid Interface Sci. 309 (2007) 511-517, https://doi.org/10.1016/j.jcis.2006.08.066. 
[211] H. Fukuzumi, T. Saito, A. Isogai, Carbohydr. Polym. 93 (2013) 172-177, https://doi.org/10.1016/j.carbpol.2012.04.069.

[212] M. Shimizu et al., Macromol. Rapid Commun. 37 (2016) 1581-1586, https:// doi.org/10.1002/marc.201600357.

[213] S. Iwamoto et al., Polym. Degrad. Stab. 95 (2010) 1394-1398, https://doi.org/ 10.1016/j.polymdegradstab.2010.01.017.

[214] A.B. Fall et al., Langmuir 27 (2011) 11332-11338, https://doi.org/10.1021/ la201947x.

[215] A. Naderi, T. Lindström, J. Sundström, Cellulose 22 (2015) 1147-1157, https:// doi.org/10.1007/s10570-015-0576-4.

[216] A. Naderi, T. Lindström, T. Pettersson, Cellulose 21 (2014) 2357-2368, https:// doi.org/10.1007/s10570-014-0329-9.

[217] J.C.F. Murray, Cellulosics, in: G.O. Phillips, P.A. Williams (Eds.), Handb. Hydrocoll., second ed., Elsevier, 2009, pp. 710-723. doi:10.1533/ 9781845695873.710

[218] C. Gómez, et al., Food Hydrocoll. 57 (2016) 178-186. doi:10.1016/J. FOODHYD.2016.01.023.

[219] T. Saarinen, M. Lille, J. Seppälä, Annu. Trans. Nord. Rheol. Soc. 17 (2009).

[220] A. Naderi, Cellulose 24 (2017) 1933-1945, https://doi.org/10.1007/s10570017-1258-1.

[221] A. Naderi, T. Lindström, Rheological measurements on nanofibrillated cellulose systems: a science in progress, in: I.H. Mondal (Ed.), Cellul. Cellul. Deriv. Synth. Modif. Appl., Nova Science Publishers Inc., 2015, pp. 187-204.

[222] O. Nechyporchuk, M.N. Belgacem, F. Pignon, Carbohydr. Polym. 112 (2014) 432-439, https://doi.org/10.1016/j.carbpol.2014.05.092.

[223] A. Karppinen et al., Cellulose 19 (2012) 1807-1819, https://doi.org/10.1007/ s10570-012-9766-5.

[224] T. Saarinen et al., Cellulose 21 (2014) 1261-1275, https://doi.org/10.1007/ s10570-014-0187-5.

[225] F. Martoïa et al., Soft Matter 11 (2015) 4742-4755, https://doi.org/10.1039/ C5SM00530B.

[226] A. Sorvari et al., Carbohydr. Polym. 106 (2014) 283-292, https://doi.org/ 10.1016/J.CARBPOL.2014.02.032.

[227] A. Naderi, T. Lindström, J. Sundström, Cellulose 21 (2014) 1561-1571, https:// doi.org/10.1007/s10570-014-0192-8.

[228] D. Tatsumi, S. Ishioka, T. Matsumoto, J. Soc. Rheol. Reoroji Gakkaishi. 30 (2002) 27-32.

[229] E. Lasseuguette, D. Roux, Y. Nishiyama, Cellulose 15 (2008) 425-433, https:// doi.org/10.1007/s10570-007-9184-2.

[230] A. Naderi et al., Cellulose 22 (2015) 1159-1173, https://doi.org/10.1007/ s10570-015-0577-3.

[231] F.C. MacKintosh, J. Käs, P.A. Janmey, Phys. Rev. Lett. 75 (1995) 4425-4428, https://doi.org/10.1103/PhysRevLett. 75.4425.

[232] G. Agoda-Tandjawa et al., Carbohydr. Polym. 80 (2010) 677-686, https://doi. org/10.1016/j.carbpol.2009.11.045

[233] L. Jowkarderis, T.G.M. van de Ven, Cellulose 21 (2014) 2511-2517, https://doi. org/10.1007/s10570-014-0292-5.

[234] H. Dong et al., Biomacromolecules 14 (2013) 3338-3345, https://doi.org/ 10.1021/bm400993f.

[235] S. Tanpichai et al., Biomacromolecules 13 (2012) 1340-1349, https://doi.org/ $10.1021 / \mathrm{bm} 300042 \mathrm{t}$

[236] L.J. Gibson, J. R. Soc. Interface 9 (2012) 2749-2766, https://doi.org/10.1098/ rsif.2012.0341.

[237] H.L. Cox, Br. J. Appl. Phys. 3 (1952) 72-79, https://doi.org/10.1088/0508$3443 / 3 / 3 / 302$

[238] D.H. Page, Tappi J. 52 (1969) 674-681.

[239] T. Lindström et al., Nord. Pulp Pap. Res. J. 31 (2016) 459-468, https://doi.org/ 10.3183/NPPRJ-2016-31-03-p459-468.

[240] T. Lindström, et al., Microfibrillated Cellulose, in: Encycl. Polym. Sci. Technol., John Wiley \& Sons Inc, Hoboken, 2014: pp. 1-34. doi:10.1002/0471440264. pst614.

[241] S. Iwamoto, A. Isogai, T. Iwata, Biomacromolecules 12 (2011) 831-836, https:// doi.org/10.1021/bm101510r.

[242] A. Walther et al., Adv. Mater. 23 (2011) 2924-2928, https://doi.org/10.1002/ adma.201100580.

[243] K.M.O. Håkansson et al., Nat. Commun. 5 (2014) 4018, https://doi.org/ 10.1038/ncomms5018.

[244] N. Mittal et al., ACS Nano 11 (2017) 5148-5159, https://doi.org/10.1021/ acsnano.7b02305.

[245] A.J. Benítez et al., Biomacromolecules 14 (2013) 4497-4506, https://doi.org/ $10.1021 / \mathrm{bm} 401451 \mathrm{~m}$

[246] M. Shimizu, T. Saito, A. Isogai, J. Memb. Sci. 500 (2016) 1-7, https://doi.org/ 10.1016/j.memsci.2015.11.002
[247] P.A. Tydeman, D.R. Wembridge, D.H. Page, Transverse Shrinkage of Individual Fibres by Micro-Radiography, Technical section of the British paper and Borad maker's association (Inc.), Cambridge, 1966.

[248] D.H. Page, Tydeman P., Physical processes occuring during the drying phase, Technical section of the British paper and Borad maker's association (Inc.), Cambridge, 1966.

[249] A. Dufresne, Nanocellulose: From Nature to High Performance Tailored Materials - Alain Dufresne - Google Books, Walter de Gruyter GmbH, Berlin, 2012. https://books.google.com.my/books?id=6Mfuk_b7gncC\&pg=PA104\& source $=$ gbs_selected_pages $\&$ cad $=2 \# \mathrm{v}=$ onepage $\& \mathrm{q} \& \mathrm{f}=$ false.

[250] A. Dufresne, S. Thomas, L.A. Pothen, Biopolymer Nanocomposite: Processing, Properties and Applications, John Wiley \& Sons Inc, New York, 2013 doi:10.1002/9781118609958

[251] A. Dufresne, Curr. Opin. Colloid Interface Sci. 29 (2017) 1-8, https://doi.org/ 10.1016/j.cocis.2017.01.004

[252] H. Kargarzadeh et al., Polymer (Guildf) 132 (2017) 368-393, https://doi.org/ 10.1016/J.POLYMER.2017.09.043.

[253] A.G. Dumanli, Curr. Med. Chem. 24 (2017) 512-528, https://doi.org/10.2174/ 0929867323666161014124008.

[254] H.-M. Ng et al., Polym. Plast. Technol. Eng. 56 (2017) 687-731, https://doi.org/ 10.1080/03602559.2016.1233277.

[255] A.J. Svagan, M.A.S.A. Samir, L.A. Berglund, Biomacromolecules 8 (2007) 25562563, https://doi.org/10.1021/BM0703160.

[256] H. Sehaqui et al., Soft Matter 7 (2011) 7342, https://doi.org/10.1039/ c1sm05325f.

[257] A.J. Benítez et al., Biomacromolecules 17 (2016) 2417-2426, https://doi.org/ 10.1021/acs.biomac.6b00533.

[258] J. Cowie, et al., Tappi J., 13(6), 2014; 57-69.

[259] J.A. Shatkin, et al., Tappi J. 13(5), 2014, 9-16.

[260] R. Sabo et al., J. Renew. Mater. 4 (2016) 297-312, https://doi.org/10.7569/ JRM.2016.634114.

[261] X. Du et al., Nano Energy 35 (2017) 299-320, https://doi.org/10.1016/J. NANOEN.2017.04.001.

[262] Y. Li et al., Nano Energy 13 (2015) 346-354, https://doi.org/10.1016/J. NANOEN.2015.02.015.

[263] F. Hoeng, A. Denneulin, J. Bras, Nanoscale 8 (2016) 13131-13154, https://doi. org/10.1039/C6NR03054H.

[264] A.W. Carpenter, C.-F. de Lannoy, M.R. Wiesner, Environ. Sci. Technol. 49 (2015) 5277-5287, https://doi.org/10.1021/es506351r.

[265] V.K. Thakur, S.I. Voicu, Carbohydr. Polym. 146 (2016) 148-165, https://doi. org/10.1016/J.CARBPOL.2016.03.030.

[266] H. Voisin, et al., Nanomater. (Basel, Switzerland) 7, 2017. doi:10.3390/nano7030057.

[267] H. Ma et al., J. Memb. Sci. 454 (2014) 272-282, https://doi.org/10.1016/J. MEMSCI.2013.11.055.

[268] H. Ma et al., ACS Macro Lett. 1 (2012) 723-726, https://doi.org/10.1021/ mz300163h.

[269] H. Zhu et al., Proc. Natl. Acad. Sci. USA 112 (2015) 8971-8976, https://doi.org/ 10.1073/pnas.1502870112.

[270] B.G. Rånby, A. Banderet, L.G. Sillén, Acta Chem. Scand. 3 (1949) 649-650.

[271] R.F. Nickerson, J.A. Habrle, Ind. Eng. Chem. 39 (1947) 1507-1512.

[272] B.G. Ranby, E. Ribi, Experientia 6 (1950) 12-14.

[273] B.L. Peng et al., Can. J. Chem. Eng. 89 (2011) 1191-1206.

[274] S.J. Eichhorn et al., J. Mater. Sci. 45 (2010) 1-33.

[275] W.Y. Hamad, Cellulose Nanocrystals: Properties, John Wiley \& Sons, Production and Applications, 2017.

[276] Future Markets Inc., The Global Market For Nanocellulose 2017 to 2027, 2017.

[277] International Organization for Standardization ISO/WD TS 21400 Determination of Cellulose Nanocrystal Sulfur and Sulfate Half-Ester Content. In ISO/TC 6 Paper, board and pulps., 2017.

[278] S. Beck, J. Bouchard, R. Berry, Biomacromolecules 13 (2012) 1486-1494.

[279] M.S. Reid, M. Villalobos, E.D. Cranston, Langmuir 33 (2017) 1583-1598.

[280] F. Cherhal, F. Cousin, I. Capron, Langmuir 31 (2015) 5596-5602.

[281] B. Medronho et al., Cellulose 19 (2012) 581-587.

[282] S. Beck-Candanedo, M. Roman, D.G. Gray, Biomacromolecules 6 (2005) 10481054.

[283] D. Bondeson, A. Mathew, K. Oksman, Cellulose 13 (2006) 171-180.

[284] H. Kargarzadeh et al., Cellulose 19 (2012) 855-866.

[285] S. Dong, M.J. Bortner, M. Roman, Ind. Crops Prod. 93 (2016) 76-87.

[286] Q. Wang, X. Zhao, J.Y. Zhu, Ind. Eng. Chem. Res. 53 (2014) 11007-11014.

[287] J. Bouchard et al., Cellulose (2016).

[288] J. Araki, M. Wada, S. Kuga, Cellulose 17 (2001) 21-27.

[289] J. Araki et al., Colloids Surfaces A Physicochem. Eng. Asp. 142 (1998) 75-82. 
[290] H. Sadeghifar et al., J. Mater. Sci. 46 (2011) 7344-7355.

[291] H.Y. Yu et al., ACS Sustain. Chem. Eng. 4 (2016) 2632-2643, https://doi.org/ 10.1021/acssuschemeng.6b00126.

[292] S. Camarero Espinosa et al., Biomacromolecules 14 (2013) 1223-1230.

[293] L. Chen et al., Green Chem. 18 (2016) 3835-3843.

[294] J.F. Revol, Carbohydr. Polym. 2 (1982) 123-134.

[295] C. Tokoh et al., Cellulose 5 (1998) 249-261.

[296] V. Favier, H. Chanzy, J.Y. Cavaillé, Macromolecules 28 (1995) 6365-6367.

[297] R.M. dos Santos et al., Ind. Crops Prod. 50 (2013) 707-714, https://doi.org/ 10.1016/j.indcrop.2013.08.049.

[298] M.F. Rosa et al., Carbohydr. Polym. 81 (2010) 83-92.

[299] B.S.L. Brito et al., Cellulose 19 (2012) 1527-1536.

[300] N. Johar, I. Ahmad, A. Dufresne, Ind. Crops Prod. 37 (2012) 93-99.

[301] S. Mueller, C. Weder, E.J. Foster, RSC Adv. 4 (2014) 907-915.

[302] E. Cudjoe et al., Carbohydr. Polym. 155 (2017) 230-241.

[303] Y. Habibi, Chem. Soc. Rev. 43 (2014) 1519-1542.

[304] N. Lin, J. Huang, A. Dufresne, Nanoscale 4 (2012) 3274-3294, https://doi.org/ 10.1039/c2nr30260h.

[305] K.H.M. Kan et al., Biomacromolecules 14 (2013) 3130-3139.

[306] X. Sun et al., Chem. Eng. J. 198-199 (2012) 476-481.

[307] S. Eyley et al., Nanoscale 7 (2015) 14413-14421.

[308] J.O. Zoppe, R.A. Venditti, O.J. Rojas, J. Colloid Interface Sci. 369 (2012) 202 209.

[309] M. Kaushik et al., Green Chem. 1 (2016) 3-7.

[310] E. Lam et al., Trends Biotechnol. 30 (2012) 283-290.

[311] L. Chen, R.M. Berry, K.C. Tam, ACS Sustain. Chem. Eng. 2 (2014) 951-958.

[312] J. Cai et al., Biomacromolecules 10 (2009) 87-94.

[313] T. Abitbol et al., Cellulose 24 (2017) 1287-1293.

[314] K. Junka et al., Biomacromolecules 15 (2014) 876-881.

[315] I. Kalashnikova et al., Biomacromolecules 13 (2012) 267-275.

[316] I. Kalashnikova et al., Langmuir 27 (2011) 7471-7479.

[317] Z. Hu et al., J. Colloid Interface Sci. 439 (2015) 139-148.

[318] A.G. Cunha et al., Langmuir 30 (2014) 9327-9335.

[319] K.R. Peddireddy et al., ACS Macro Lett. 5 (2016) 283-286.

[320] I. Capron, B. Cathala, Biomacromolecules 14 (2013) 291-296.

[321] Z. Hu et al., ACS Macro Lett. 5 (2015) 185-789.

[322] S.A. Kedzior, H.S. Marway, E.D. Cranston, Macromolecules 50 (2017) 2645 2655.

[323] Z. Dastjerdi, E.D. Cranston, M.A. Dubé, Macromol. React. Eng. 201700013 (2017) $1-8$

[324] Z. Hu et al., Biomacromolecules 17 (2016) 4095-4099.

[325] Y. Boluk et al., Colloids Surfaces A Physicochem. Eng. Asp. 377 (2011) 297303.

[326] Q. Wu et al., J. Appl. Polym. Sci. 40525 (2014).

[327] I. Kalashnikova et al., Soft Matter 9 (2013) 952-959.

[328] R. Rusli et al., Biomacromolecules 12 (2011) 1363-1369.

[329] K.J. De France, T.R. Hoare, E.D. Cranston, Chem. Mater. 29 (2017) 46094631.

[330] X. Yang, E.D. Cranston, Chem. Mater. 35 (2014) 6016-6025.

[331] J.P.F. Lagerwall et al., NPG Asia Mater. 6 (2014) e80.

[332] J.-F.F.J. Revol et al., Int. J. Biol. Macromol. 14 (1992) 170-172.

[333] J.F. Revol, L. Godbout, D.G. Gray, J. Pulp Pap. Sci. 24 (1998) 146-149.

[334] X.M. Dong et al., Langmuir 12 (1996) 2076-2082.

[335] M. Giese et al., Angew. Chem. Int. Ed. 54 (2015) 2888-2910.

[336] K.E. Shopsowitz, et al., Nature (London, United Kingdom). 468 (2010) 422 426.

[337] Y. Li et al., Nat. Commun. 7 (2016) 12520.

[338] R.M. Parker et al., ACS Nano 10 (2016) 8443-8449.

[339] P.-X. Wang, W.Y. Hamad, M.J. MacLachlan, Nat. Commun. 7 (2016) 11515.

[340] D.G. Gray, X. Mu, Materials (Basel) 8 (2015) 7873-7888.

[341] A. Mujica-Garcia et al., RSC Adv. 6 (2016) 9221-9231, https://doi.org/10.1039/ C5RA22818B.

[342] S. Geng, M.M.U. Haque, K. Oksman, Compos. Sci. Technol. 126 (2016) 35-42.

[343] M. Worarin et al., Macromolecules 50 (2017) 2364-2374.

[344] J. Sapkota et al., Macromol. Mater. Eng. 302 (2017) 1600300.

[345] Y. Cao et al., Cem. Concr. Compos. 56 (2015) 73-83.

[346] J. You et al., Biomacromolecules 17 (2016) 2839-2848.

[347] B. Frka-Petesic, B. Jean, L. Heux, EPL (Europhysics Lett. 107 (2014) 28006 doi:10.1209/0295-5075/107/28006.

[348] B. Frka-Petesic et al., Macromolecules 48 (2015) 8844-8857.

[349] K.J. De France et al., Langmuir 32 (2016) 7564-7571.

[350] B. Frka-Petesic et al., Adv. Mater. 1701469 (2017) 1-7.

[351] I. Kvien, K. Oksman, Appl. Phys. A 87 (2007) 641-643.
[352] T. Abitbol, E.D. Cranston, Directed assembly of oriented cellulose nanocrystal films, in: Handb. Green Mater., World Scientific Publishing Company, 2014, pp. 79-103.

[353] J.M. Dugan et al., Acta Biomater. 9 (2013) 4707-4715.

[354] M. Chau et al., Chem. Mater. 28 (2016) 3406-3415.

[355] X. Yang et al., Adv. Mater. 27 (2015) 6104-6109.

[356] N. Grishkewich et al., Curr. Opin. Colloid Interface Sci. 29 (2017) 32-45.

[357] L. Wang, et al., Adv. Energy Mater. (2017). https://doi.org/10.1002/aenm. 201700130.

[358] V. Lafitte, Schlumberger, Application of Cellulose Nanocrystals in Oilfield Gravel Packing Fluid, Conf. Tech. Assoc. Pulp Pap. Inst. Nanotechnol. Div. (2017) Montreal, Canada.

[359] S.N. Molnes et al., Ind. Crops Prod. 93 (2016) 152-160.

[360] E.B. Heggset, G. Chinga-Carrasco, K. Syverud, Carbohydr. Polym. 157 (2017) 114-121.

[361] S. Shafiei-Sabet, W.Y. Hamad, S.G. Hatzikiriakos, Cellulose 21 (2014) $3347-$ 3359.

[362] M. Roman, Ind. Biotechnol. 11 (2015) 25-33.

[363] K.A. Mahmoud et al., ACS Appl. Mater. Interfaces 2 (2010) 2924-2932, https:// doi.org/10.1021/am1006222.

[364] Y. Liu et al., Acc. Chem. Res. 46 (2013) 702-713, https://doi.org/10.1021/ ar300028m.

[365] A. Nan et al., Nano Lett. 8 (2008) 2150-2154, https://doi.org/10.1021/ nl0802741.

[366] F. Schlenk et al., Arch. Toxicol. 91 (2017) 3271-3286, https://doi.org/10.1007/ s00204-017-1968-z.

[367] Y. Pötzinger, et al., Bacterial nanocellulose as a drug delivery system for nucleic acids, in: DPhG Annu. Meet., Düsseldorf, 2015.

[368] K.B. Male et al., Nanoscale 4 (2012) 1373-1379.

[369] S. Dong, Nano Life 2 (2012) 12410061-124100611, https://doi.org/10.1142/ S1793984412410061.

[370] S. Camarero-Espinosa et al., Fibers 4 (2016) 21, https://doi.org/ 10.3390/fib4030021.

[371] C. Endes et al., Biomacromolecules 16 (2015), https://doi.org/10.1021/acs biomac.5b00055. 150401095226002.

[372] T. Kovacs et al., Nanotoxicology 4 (2010) 255-270.

[373] W. Wang, J. Jung, Y. Zhao, Carbohydr. Polym. 157 (2017) 1246-1253.

[374] E. Dickinson, Trends Food Sci. Technol. 24 (2012) 4-12, https://doi.org/ 10.1016/j.tifs.2011.09.006.

[375] T. Kuhnt et al., Polym. Chem. 6 (2015) 6553-6562, https://doi.org/10.1039/ C5PY00944H.

[376] Q. Chunxia Wen, Carbohydr. Polym. 112 (2014) 695-700. doi: 10.1016/ j.foodchem.2017.04.028.

[377] Y.Z. Zilong, Food Chem. 232 (2017) 359-368. doi: 10.1016/ j.foodchem.2017.04.028.

[378] J. Jung et al., Sci. Hortincult. 200 (2016) 161-169.

[379] Y.Z. Zilong, J. Food Sci. 82 (2017) 453-462.

[380] N.M. Stark, J. Renwable Mater. 4 (2016) 313-326.

[381] N. Mohammed et al., Cellulose 22 (2015) 3725-3738, https://doi.org/10.1007/ s10570-015-0747-3.

[382] A. Mautner et al., React. Funct. Polym. 86 (2015) 209-214, https://doi.org/ 10.1016/j.reactfunctpolym.2014.09.014.

[383] Z. Karim et al., J. Memb. Sci. 514 (2016) 418-428, https://doi.org/10.1016/j. memsci.2016.05.018.

[384] J.-J. Wang et al., J. Mater. Chem. A 5 (2017) 16289-16295, https://doi.org/ 10.1039/C7TA00501F.

[385] N. Mohammed et al., ACS Sustain. Chem. Eng. 4 (2016) 6167-6176, https:// doi.org/10.1021/acssuschemeng.6b01674.

[386] J. Lu et al., Int. J. Biol. Macromol. 93 (2016) 547-556, https://doi.org/10.1016/ j.ijbiomac.2016.09.004.

[387] H. Zhu et al., Adv. Mater. 28 (2016) 7652-7657, https://doi.org/10.1002/ adma.201601351.

[388] N. Bossa et al., Environ. Sci. Nano. 4 (2017) 1294-1303.

[389] A. Ben Mabrouk et al., Compos. Sci. Technol. 71 (2011) 818-827.

[390] Z. Dastjerdi, E.D. Cranston, M.A. Dubé, Int. J. Adhes. Adhes. https://doi.org/ 10.1016/j.ijadhadh.2017.11.009.

[391] C.E. Lipscomb, K.M. Lewandowski, C.S. Thomas, J. Seth, L. Qie, PRESSURESENSITIVE ADHESIVE CONTAINING NANOCRYSTALLINE CELLULOSE, US 2017/0283669 A1, 2017.

[392] T. Abitbol et al., Green Mater. 2 (2014) 206-221, https://doi.org/10.1680/ gmat.14.00017.

[393] N. Girouard et al., Polymer (Guildf) 68 (2015) 111-121.

[394] A. Santamaria-Echart et al., Carbohydr. Polym. 151 (2016) 1203-1209. 
[395] M.A.C.M. Haniffa, et al., Polymer (Guildf) 8 (2016) 246. doi:doi:10.3390/ polym8070246.

[396] J. Huang et al., RSC Adv. 7 (2017) 20152-20159.

[397] A. Kaboorani et al., Prog. Org. Coat. 104 (2017) 91-96.

[398] A. Cataldi et al., Prog. Org. Coat. 106 (2017) 128-136.

[399] P. Lu, Y. Lo, Nanotechnology 20 (2009), https://doi.org/10.1088/0957-4484/ 20/41/415604.

[400] C. Zhou et al., Biomacromolecules 12 (2011) 2617-2625, https://doi.org/ 10.1021/bm200401p.

[401] C. Xiang et al., J. Appl. Polym. Sci. 127 (2013) 79-86, https://doi.org/10.1002/ app.36943.

[402] M. Ago, J.E. Jakes, O.J. Rojas, ACS Appl. Mater. Interfaces 5 (2013) 11768 11776, https://doi.org/10.1021/am403451w.

[403] W.L.E. Magalhães, X. Cao, L.A. Lucia, Langmuir 25 (2009) 13250-13257, https://doi.org/10.1021/la901928j.

[404] Marketsandmarkets.com, Nanocellulose Market by Type, Application and Geography - 2019 | MarketsandMarkets, 2015.

[405] J.O. Zoppe, L.-S. Johansson, J. Seppälä, Carbohydr. Polym. 126 (2015) 23-31, https://doi.org/10.1016/J.CARBPOL.2015.03.005.

[406] K. Littunen et al., Eur. Polym. J. 75 (2016) 116-124, https://doi.org/10.1016/J. EURPOLYMJ.2015.12.008.

[407] P. Laurén et al., PLoS One 12 (2017) e0183487, https://doi.org/10.1371/ journal.pone.0183487.

[408] K. Littunen et al., Carbohydr. Polym. 84 (2011) 1039-1047, https://doi.org/ 10.1016/J.CARBPOL.2010.12.064.

[409] P.K. Kulkarni, S.A. Dixit, U.B. Singh, Am. J. Drug Discov. Dev. 2 (2012) 72-86, https://doi.org/10.3923/ajdd.2012.72.86.

[410] M. Cairul et al., Sains Malaysiana 41 (2012) 561-568.

[411] C. Wiegand et al., J. Mater. Sci. Mater. Med. 26 (2015) 245, https://doi.org/ 10.1007/s10856-015-5571-7.

[412] S. Sukhtezari et al., Carbohydr. Polym. 156 (2017) 340-350, https://doi.org/ 10.1016/j.carbpol.2016.09.058.

[413] E. Trovatti et al., Int. J. Pharm. 435 (2012) 83-87, https://doi.org/10.1016/j. ijpharm.2012.01.002.

[414] R. Kolakovic et al., Eur. J. Pharm. Biopharm. 82 (2012) 308-315, https://doi. org/10.1016/j.ejpb.2012.06.011.

[415] R. Kolakovic et al., Int. J. Pharm. 430 (2012) 47-55, https://doi.org/10.1016/j ijpharm.2012.03.031.

[416] N. Drogat et al., Bioorg. Med. Chem. Lett. 22 (2012) 3648-3652, https://doi org/10.1016/j.bmcl.2012.04.044.

[417] A. Taheri, M. Mohammadi, Chem. Biol. Drug Des. 86 (2015) 102-106, https:// doi.org/10.1111/cbdd.12466.

[418] N. Lin, A. Dufresne, Biomacromolecules 14 (2013) 871-880, https://doi.org/ 10.1021/bm301955k.

[419] N. Lin et al., Colloids Surfaces B Biointerfaces 85 (2011) 270-279, https://doi. org/10.1016/j.colsurfb.2011.02.039.

[420] S. Moritz et al., Int. J. Pharm. 471 (2014) 45-55, https://doi.org/10.1016/j. ijpharm.2014.04.062.

[421] A. Khalid et al., Carbohydr. Polym. 164 (2017) 214-221, https://doi.org/ 10.1016/j.carbpol.2017.01.061.

[422] B.V. Mohite, R.K. Suryawanshi, S.V. Patil, Cellul. Chem. Technol. Cellul. Chem. Technol. 50 (2016) 219-223.

[423] N.H.C.S. Silva et al., Carbohydr. Polym. 106 (2014) 264-269, https://doi.org/ 10.1016/j.carbpol.2014.02.014.

[424] Y. Numata et al., Polym. J. 41 (2009) 524-525, https://doi.org/10.1295/polymj. PJ2009035.

[425] A. Müller et al., J. Pharm. Sci. 102 (2013) 579-592, https://doi.org/10.1002/ jps.23385.

[426] Y. Numata, L. Mazzarino, R. Borsali, Int. J. Pharm. 486 (2015) 217-225, https:// doi.org/10.1016/j.ijpharm.2015.03.068.

[427] L. Huang et al., J. Mater. Chem. B 1 (2013) 2976-2984, https://doi.org/ 10.1039/c3tb20149j.

[428] P. Scholz, et al., Freeze dried bacterial nanocellulose as potential drug delivery system for peroral application of sensitive drugs, in: CRS Ger. Chapter Annu. Meet., Würzburg, Germany, 2012. doi:10.1002/jps.23385.
[429] A. Yoshino et al., Acta Biomater. 9 (2013) 6116-6122, https://doi.org/10.1016/ j.actbio.2012.12.022.

[430] Y. Wang, L. Chen, Carbohydr. Polym. 83 (2011) 1937-1946, https://doi.org/ 10.1016/j.carbpol.2010.10.071.

[431] J. Zhao et al., ACS Appl. Mater. Interfaces 7 (2015) 2607-2615, https://doi.org/ $10.1021 / \mathrm{am} 507601 \mathrm{~m}$.

[432] J.K. Letchford et al., Int. J. Nanomedicine. 6 (2011) 321-330, https://doi.org/ 10.2147/IJN.S16749.

[433] G.M.A. Ndong Ntoutoume et al., Carbohydr. Polym. 164 (2017) 258-267, https://doi.org/10.1016/j.carbpol.2017.02.004.

[434] W. Shao et al., Carbohydr. Polym. 145 (2016) 114-120, https://doi.org/ 10.1016/j.carbpol.2016.02.065.

[435] H. Luo et al., Curr. Appl. Phys. 17 (2017) 249-254, https://doi.org/10.1016/ j.cap.2016.12.001.

[436] R.-D. Pavaloiu et al., Int. J. Biol. Macromol. 68 (2014) 117-124, https://doi.org/ 10.1016/j.ijbiomac.2014.04.040.

[437] S.P. Akhlaghi, R.C. Berry, K.C. Tam, Cellulose 20 (2013) 1747-1764.

[438] H. Valo et al., Eur. J. Pharm. Sci. 50 (2013) 69-77, https://doi.org/10.1016/j. ejps.2013.02.023.

[439] E. Kaplan et al., J. Biomater. Tissue Eng. 4 (2014) 543-549, https://doi.org/ 10.1166/jbt.2014.1198.

[440] N. Ahmad et al., Mol. Pharm. 11 (2014) 4130-4142.

[441] L.M.P. Sampaio et al., Carbohydr. Polym. 145 (2016) 1-12, https://doi.org/ 10.1016/j.carbpol.2016.03.009.

[442] S.-C. Wu, S.-M. Wu, F.-M. Su, J. Chem. Technol. Biotechnol. 92 (2017) 109114, https://doi.org/10.1002/jctb.4994.

[443] C.A. Cozzolino et al., Colloids Surfaces B Biointerfaces 110 (2013) 208-216, https://doi.org/10.1016/j.colsurfb.2013.04.046.

[444] R. Dash et al., RSC Adv. 2 (2012) 3403-3409, https://doi.org/10.1039/ c2ra01071b.

[445] J.O. Zoppe et al., Biomacromolecules 15 (2014) 1534-1542, https://doi.org/ 10.1021/bm500229d.

[446] M. Rouabhia et al., ACS Appl. Mater. Interfaces 6 (2014) 1439-1446, https:// doi.org/10.1021/am4027983.

[447] W. Hu et al., Carbohydr. Polym. 101 (2014) 1043-1060, https://doi.org/ 10.1016/j.carbpol.2013.09.102.

[448] X. Qiu, S. Hu, Materials (Basel) 6 (2013) 738-781, https://doi.org/ 10.3390/ma6030738

[449] R. Alosmanov, K. Wolski, S. Zapotoczny, Cellulose 24 (2017) 285-293, https:// doi.org/10.1007/s10570-016-1120-x.

[450] X. Shi et al., RSC Adv. 4 (2014) 47056-47065, https://doi.org/10.1039/ C4RA09640A.

[451] L. Saïdi et al., Carbohydr. Polym. 169 (2017) 357-365.

[452] S.Y. Ooi, I. Ahmad, M.C.I.M. Amin, Ind. Crops Prod. 93 (2016) 227-234, https://doi.org/10.1016/j.indcrop.2015.11.082.

[453] R.-D. Păvăloiu, A. Stoica-Guzun, T. Dobre, U.P.B. Sci. Bull., Ser. B. 77 (2015) 5362.

[454] G. Chinga-Carrasco, K. Syverud, J. Biomater. Appl. 29 (2014) 423-432, https:/ doi.org/10.1177/0885328214531511.

[455] W. Fang et al., Biomacromolecules 18 (2017) 1866-1873, https://doi.org/ 10.1021/acs.biomac.7b00294.

[456] Y. Bai et al., Carbohydr. Polym. 89 (2012) 1207-1214.

[457] Y. Chen et al., Biomacromolecules 9 (2008) 2609-2614, https://doi.org/ 10.1021/bm800484e.

[458] C. Chang et al., Eur. Polym. J. 46 (2010) 92-100, https://doi.org/10.1016/j. eurpolymj.2009.04.033.

[459] M.L. Cacicedo et al., J. Appl. Biomed. 13 (2015) 239-248.

[460] X. Zhang et al., Polymer (Guildf). 51 (2010) 4398-4407, https://doi.org/ 10.1016/i.polymer.2010.07.025.

[461] J. Miller, Nanocellulose Producers, Products, and Applications: A Guide for End Users, TAPPI, 2017.

[462] P. Svending, C. Nutbeem, I. Elliott, Mineral filler solutions for cost and quality enhancement in graphic papers, in: PTS Pap. Symp., Munich, Germany, 2010.

[463] H. Bian et al., Exp. 119 (2017). e55079-e55079.. 